PNNL-18386

\title{
Human Factors Evaluation of Advanced Electric Power Grid Visualization Tools
}

Frank L. Greitzer

Peter M. Dauenhauer

Tamara G. D. Wierks

Robin Podmore

April 30, 2009

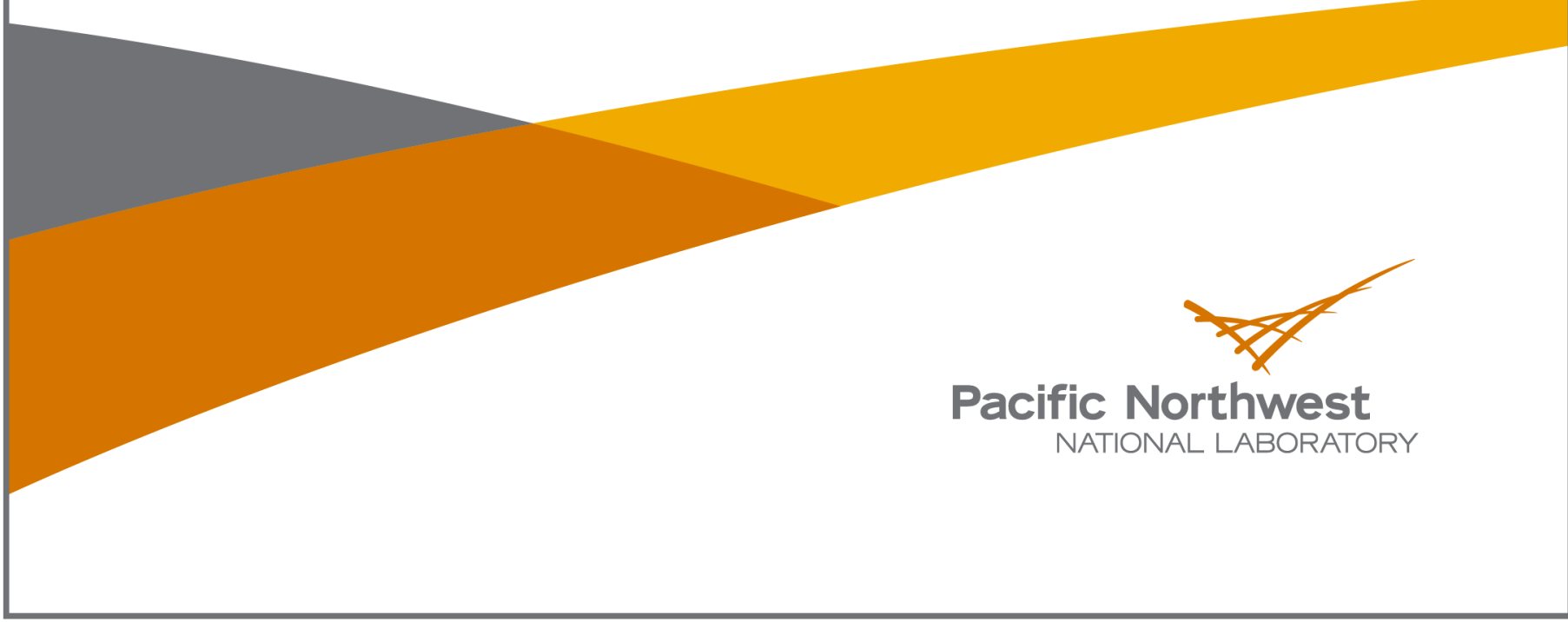




\section{DISCLAIMER}

This report was prepared as an account of work sponsored by an agency of the United States Government. Neither the United States Government nor any agency thereof, nor Battelle Memorial Institute, nor any of their employees, makes any warranty, express or implied, or assumes any legal liability or responsibility for the accuracy, completeness, or usefulness of any information, apparatus, product, or process disclosed, or represents that its use would not infringe privately owned rights. Reference herein to any specific commercial product, process, or service by trade name, trademark, manufacturer, or otherwise does not necessarily constitute or imply its endorsement, recommendation, or favoring by the United States Government or any agency thereof, or Battelle Memorial Institute. The views and opinions of authors expressed herein do not necessarily state or reflect those of the United States Government or any agency thereof.

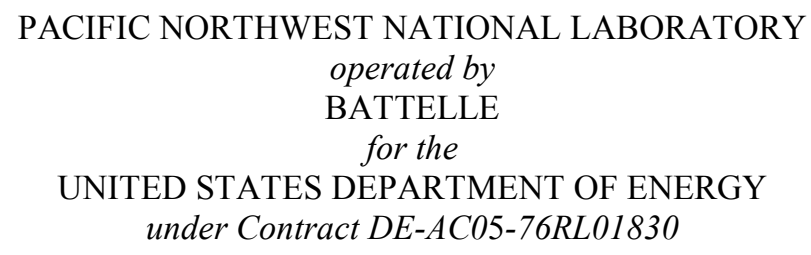

Printed in the United States of America Available to DOE and DOE contractors from the Office of Scientific and Technical Information, P.O. Box 62, Oak Ridge, TN 37831-0062; ph: (865) 576-8401 fax: (865) 576-5728 email: reports@adonis.osti.gov

\footnotetext{
Available to the public from the National Technical Information Service, U.S. Department of Commerce, 5285 Port Royal Rd., Springfield, VA 22161 ph: (800) 553-6847 fax: (703) 605-6900

email: orders@ntis.fedworld.gov online ordering: http://www.ntis.gov/ordering.htm
} 


\section{Acknowledgment}

We gratefully acknowledge the support and input provided by the Principal Investigators and their research teams involved in the development of the visualization methods and analytic tools examined in this study: Ross T. Guttromson, Zhenyu (Henry) Huang, Pak C. Wong, Ning Zhou. 
THIS PAGE INTENTIONALLY LEFT BLANK 


\section{Contents}

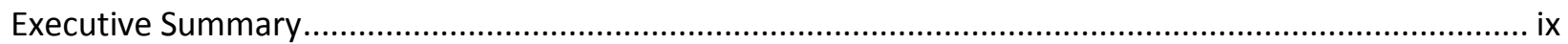

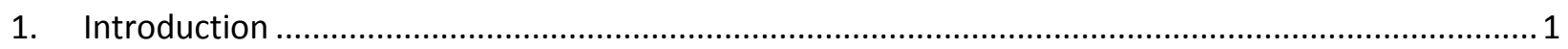

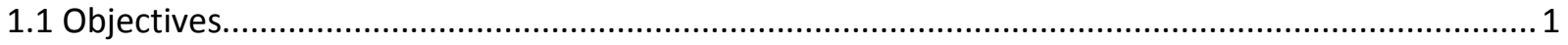

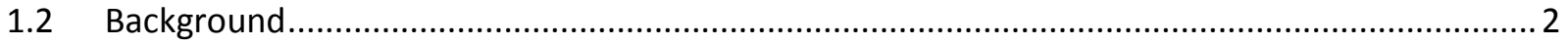

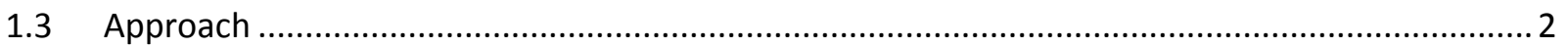

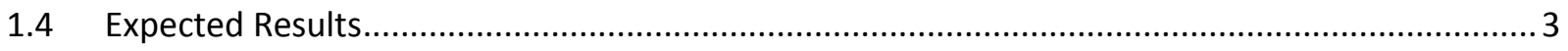

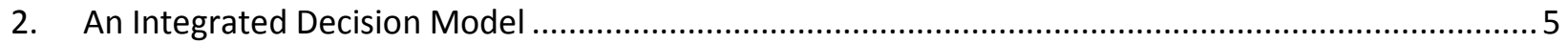

3. Potential benefits of the Visualization Tools ............................................................................ 7

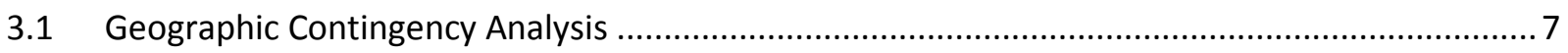

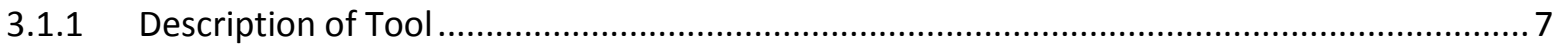

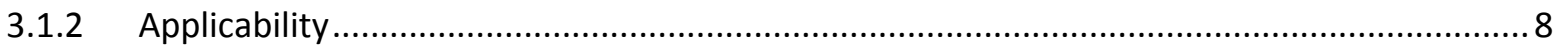

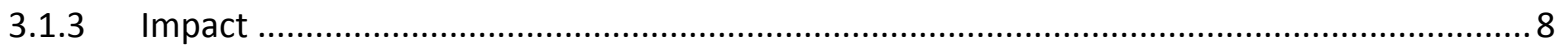

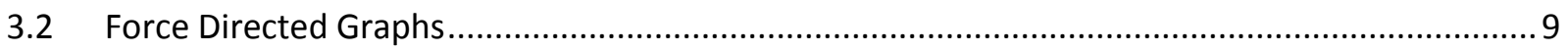

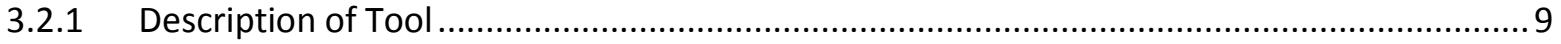

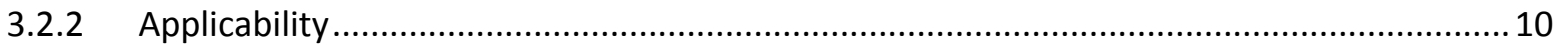

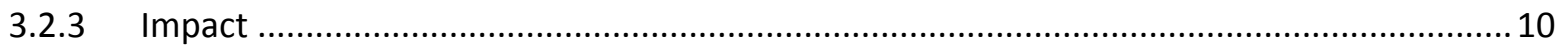

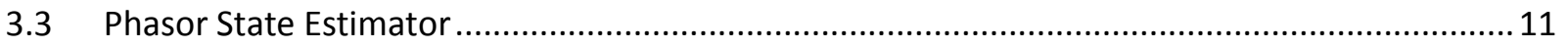

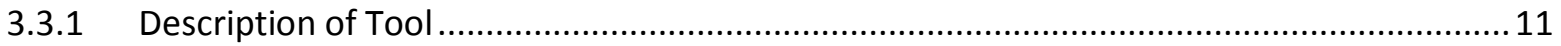

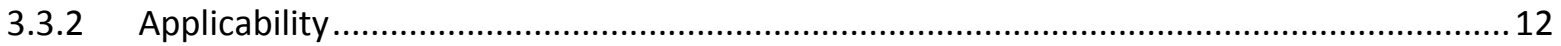

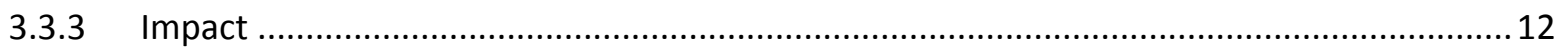

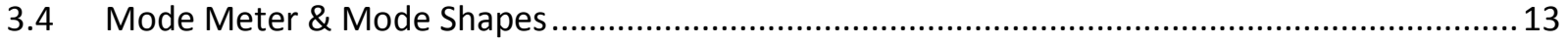

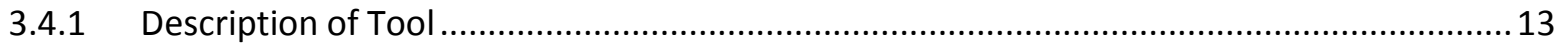

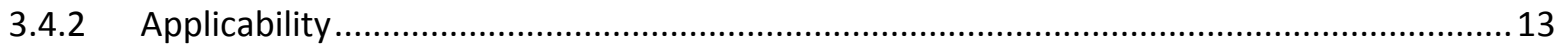

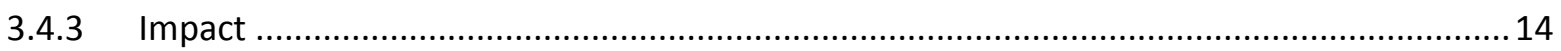

4. Simulation and Test Environment............................................................................................ 17

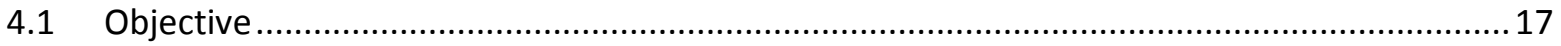

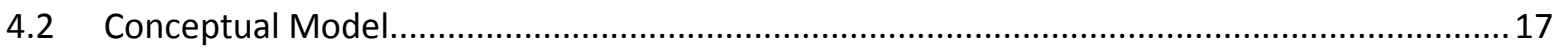

4.3 Pretest-Posttest Nonequivalent Groups Quasi-Experimental Design ................................... 17

4.4 General Information on Experiment Design ................................................................... 18 


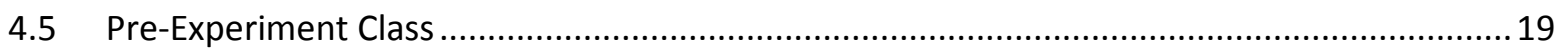

4.6 General Information on Performance Measures ................................................................... 19

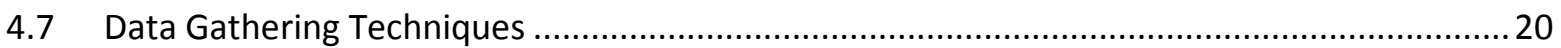

5. Design of Individual Experiments to Demonstrate Benefits........................................................ 21

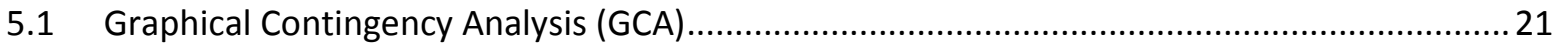

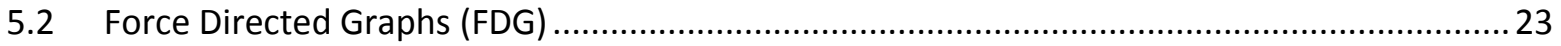

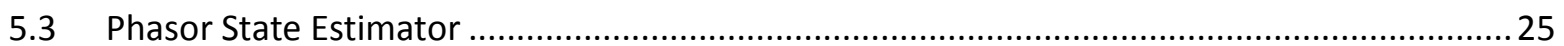

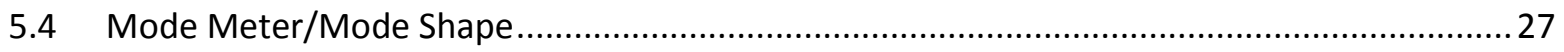

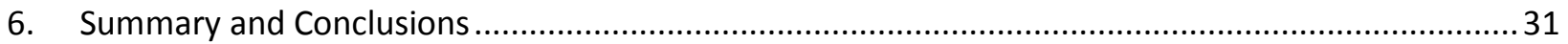

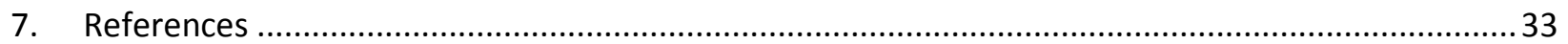

Appendix A: Application of Integrated Decision Model .................................................................. A-1

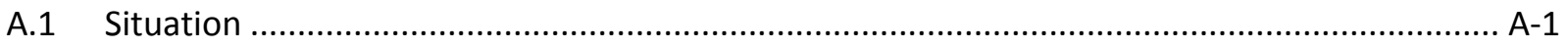

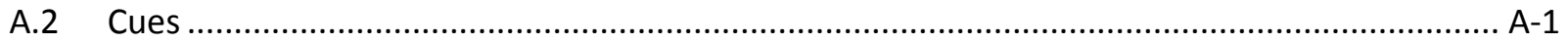

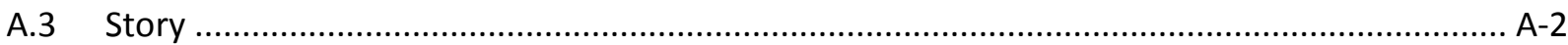

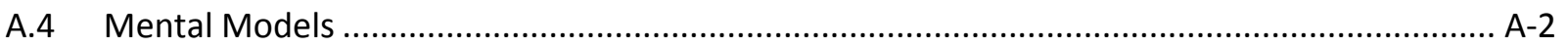

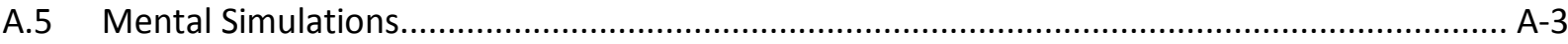

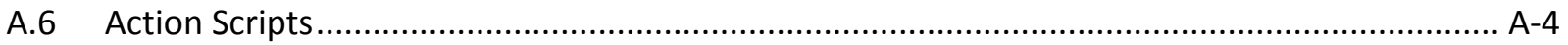

Appendix B: Topics Covered During Pre Experiment Class .............................................................. B-1

Appendix C: Graphical Contingency Analysis Experiment-Technical Details ........................................

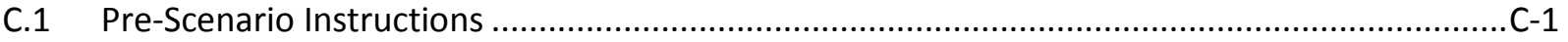

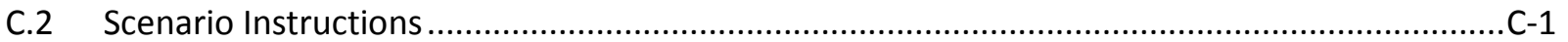

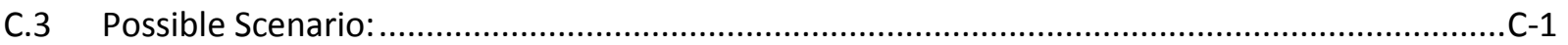

C.4 Human Factor Performance Measures …...............................................................................

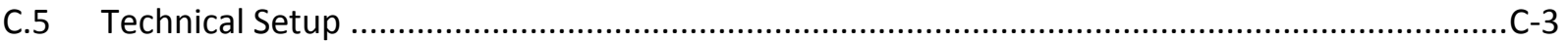

Appendix D: Force Directed Graph Experiment-Technical Details................................................. D -1

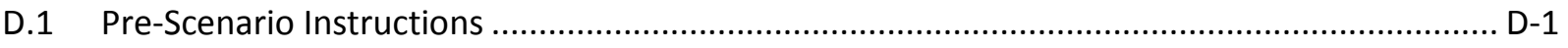

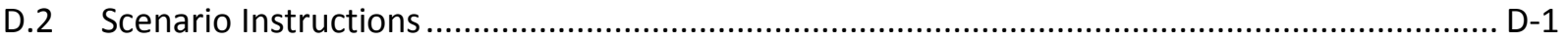

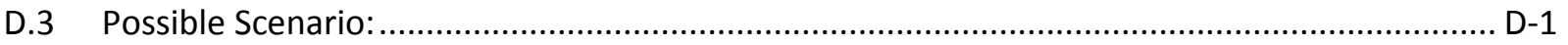

D.4 Human Factor Performance Measures ............................................................................... D-2

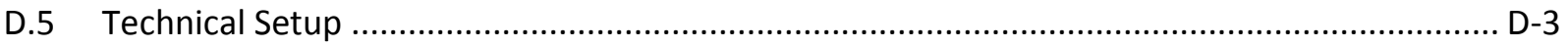

Appendix E: Phasor State Estimator Experiment-Technical Details .................................................... E-1

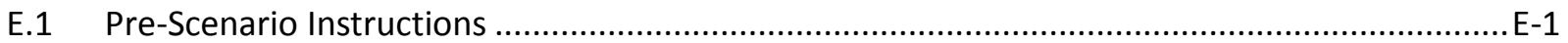




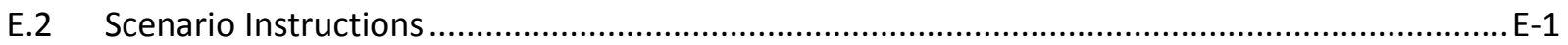

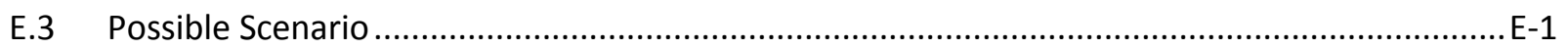

E.4 Human Factor Performance Measures ................................................................................ E-2

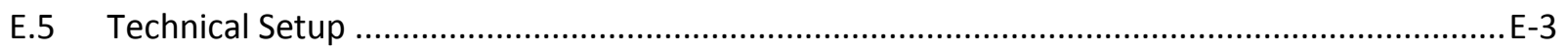

Appendix F: Mode Meter/Mode Shapes Experiment-Technical Details ............................................... F-1

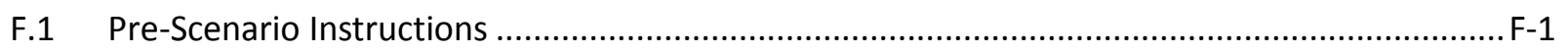

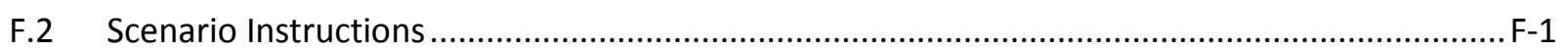

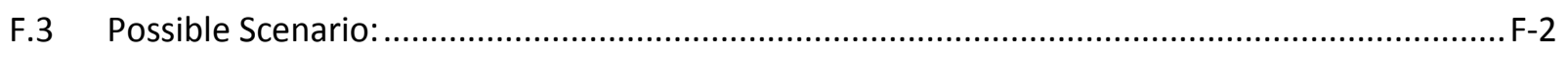

F.5 Human Factor Performance Measures …........................................................................ F-3

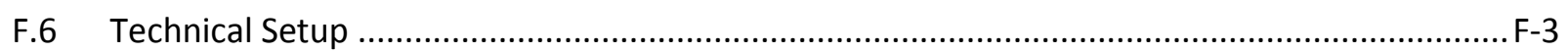


THIS PAGE INTENTIONALLY LEFT BLANK 


\section{Executive Summary}

Despite advances in technology, power system operators must assimilate overwhelming amounts of data to keep the electric utility grid operating. Analyses of recent blackouts have demonstrated the need to enhance the operator's ability to understand the state of the system and anticipate possible problems. To confront this escalation of complexity, new paradigms, tools, and visualizations are needed to enhance and improve operations. The research community is hard at work developing new tools and visualizations to relieve the information processing burdens on decision makers, but the Department of Energy (DOE) and power grid utility stakeholders rightly demand that proposed solutions be evaluated to demonstrate their utility before deploying even more displays and visualizations that may have the unwanted potential of increasing the operator's workload.

The Pacific Northwest National Laboratory (PNNL) has an ongoing research program aimed at developing advanced analyses and visualizations to enhance operator situation awareness and decision making in normal and emergency power grid operations. Acknowledging the need for validation studies, PNNL has initiatied a human factors test and evaluation program within its Electricity Infrastructure Operations Center (EIOC) to initially conduct appropriate validation studies using internally-developed visualization tools, and eventually to make this test bed available for test and evaluation of tools, visualizations, and training approaches developed by outside R\&D teams and vendors on behalf of the DOE or electric power industry.

This report describes initial human factors evaluation of four visualization tools (Graphical Contingency Analysis, Force Directed Graphs, Phasor State Estimator and Mode Meter/ Mode Shapes) developed by PNNL, and proposed test plans that may be implemented to evaluate their utility in scenario-based experiments. The impact assessment focuses on the extent of facilitation of operator performance by the proposed analysis and visualization tools, examined within a human factors/performance evaluation framework based on a sophisticated cognitive approach to understanding and measuring performance using cognitive task analysis and naturalistic decision making concepts. The basis of this approach is the Integrated Decision Model, which the authors have adapted from current models of naturalistic decision making. The model describes decision making by articulating several cognitive processing stages, conceptualized using mediating variables such as mental models. The first stage is situation assessment, where mental models and cues from the environment are used to build an accurate story that describes the situation. The next stage is the determination of which action to take in order to positively affect the situation. Mental simulations, based on mental models, help predict the outcome of different actions and point towards an optimal decision. Finally, the new situation is assessed and a determination is made as to whether the situation is resolved or if the pattern needs repeating.

The primary purpose of this study was to conduct an initial assessment of the four visualization tools using a heuristic evaluation technique that identifies the expected operational utility and the most likely beneficiary of the tool. This analysis identified the user population (or "level of analysis") that is most appropriate for each tool-for example, whether the impact is on 
Reliability Coordinators, Transmission Operators or Planning Engineers, or perhaps higher level policy decision makers. The results of this analysis are summarized in the following table.

\begin{tabular}{|c|c|c|}
\hline Visualization Tool & Applicability to... & Impact/benefit of the tool \\
\hline $\begin{array}{l}\text { Geographic Contingency } \\
\text { Analysis }\end{array}$ & $\begin{array}{ll}- & \text { Reliability Coordinator } \\
\text { - } & \text { Transmission Operator }\end{array}$ & $\begin{array}{l}\text { Quicker and more } \\
\text { comprehensive situation } \\
\text { awareness, identification of } \\
\text { weak spots and mitigation } \\
\text { options. }\end{array}$ \\
\hline Force Directed Graphs & $\begin{array}{ll}\text { - } & \text { Reliability Coordinator } \\
\text { - } & \text { Transmission Operator } \\
\text { - } & \text { System Planners }\end{array}$ & 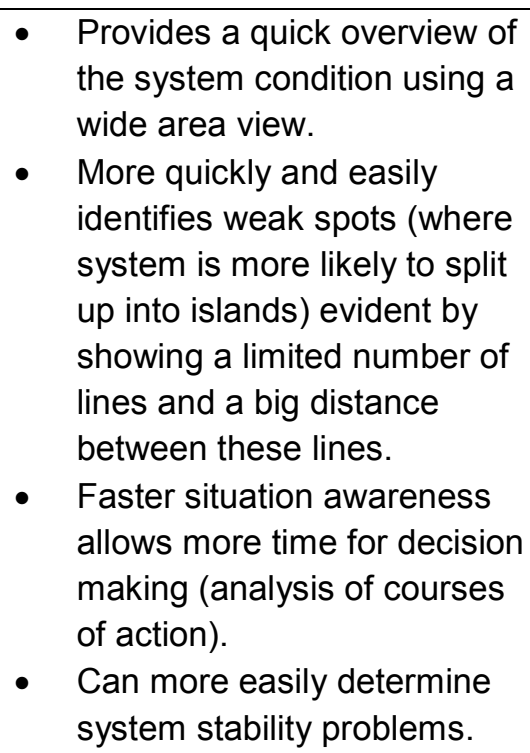 \\
\hline Phasor State Estimator & $\begin{array}{ll}\text { - } & \text { Reliability Coordinator } \\
\text { - } & \text { Transmission Operator }\end{array}$ & $\begin{array}{ll}\text { - } & \text { Facilitates detection and } \\
\text { isolation of network topology } \\
\text { errors } \\
\text { - } \quad \text { Facilitates identification of } \\
\text { bad data. } \\
\text { - Can provide a check of } \\
\text { SCADA data } \\
\text { Can provide a foundation for } \\
\text { several other tools: } \\
\text { Contingency Analysis, Mode } \\
\text { Meter/Mode Shape, Force } \\
\text { Directed Graphs, Smart } \\
\text { islanding schemes, Wide } \\
\text { area power flow views. }\end{array}$ \\
\hline Mode Meter/Mode Shape & $\begin{array}{ll}\text { - } & \text { Reliability Coordinator } \\
\text { - } & \text { Transmission Operator } \\
\text { - } & \text { Generator Operator } \\
\text { - } & \text { Balancing Authority } \\
\text { - } & \text { Planning Engineer }\end{array}$ & $\begin{array}{l}\text { Most operators are } \\
\text { completely in the dark under } \\
\text { conditions of dynamic } \\
\text { instability }\end{array}$ \\
\hline
\end{tabular}


A second purpose of this study was to define a more indepth analysis of the visualization tools that may be conducted within specific experimental studies designed to measure the impact on decision making performance. Current practice in human factors evaluations of situation awareness and operational decision making performance typically involves pausing a scenario to ask the decision maker questions directed at identifying whether or not certain cues or concepts have been apprehended (e.g., Endsley's Situation Awareness Global Assessment Technique, or SAGAT). Our proposed experimental assessment method seeks to complement this practice by attempting to examine the operator's use of requisite mental models and associated mediating variables by defining observable responses as proxies for these variables. The proposed experiments will compare performance of an experimental group and a control gourp using a simulated scenario in which the experimental group has access to the visualization tool(s) and the control group does not have use of the tool(s). Participants will be power system professionals currently employed as a transmission operator, balancing operator, reliability coordinator, or a combination of the three roles.

The scope of the present report is to specify the experiments that are proposed and the expected outcomes. A follow-on study will conduct the experiments and report results. The expected outcome of the proposed experiments is an assessment of the nature and extent of the impact of power grid visualization tools developed by PNNL. Specifically, according to the Integrated Decision Model and mental models identified with the tools, the experiments will seek to determine if the visualizations trigger appropriate mental models needed by system operators to understand the state of the system in real time and promote effective and timely actions. The expectation is that the framework and experimental method specified in the proposed study will be useful for identifying performance impacts and utility of power grid analysis and visualization tools developed not only by PNNL but also by other R\&D groups, with evaluations that may be conducted on behalf of industry and DOE stakeholders. Ultimately, it is hoped that the human factors and test/evaluation methodology, applied within the PNNL EIOC, will lead to the deployment of more effective tools and visualizations that will ultimately improve the performance of power grid operators, supervisory personnel, and regulatory policy makers through enhanced situation awareness and cognitive decision support, and ultimately create more reliable and secure electric power grid interconnection and operations. 
THIS PAGE INTENTIONALLY LEFT BLANK 


\section{Introduction}

Despite advances in technology, power system operators must assimilate overwhelming amounts of data to keep the electric utility grid operating. Analyses of recent blackouts have demonstrated the need to enhance the operator's ability to understand the state of the system and anticipate possible problems. To confront this escalation of complexity, new paradigms, tools, and visualizations are needed to enhance and improve operations. The research community is hard at work developing new tools and visualizations to relieve the information processing burdens on decision makers, but the Department of Energy (DOE) and power grid utility stakeholders rightly demand that proposed solutions be evaluated to demonstrate their utility before deploying even more displays and visualizations that may have the unwanted potential of increasing the operator's workload.

The Pacific Northwest National Laboratory (PNNL) has an ongoing research program aimed at developing advanced analyses and visualizations to enhance operator situation awareness and decision making in normal and emergency power grid operations. Acknowledging the need for validation studies, PNNL has initiatied a human factors test and evaluation program within its Electricity Infrastructure Operations Center (EIOC) to initially conduct appropriate validation studies using internally-developed visualization tools, and eventually to make this test bed available for test and evaluation of tools, visualizations, and training approaches developed by outside R\&D teams and vendors on behalf of the DOE or electric power industry.

This report documents a human factors analysis of advanced visualization methods developed by research teams at PNNL to increase the effectiveness of power grid situation awareness and operational decision making in normal and emergency power grid operation. The research conducted by PNNL, with support by Incremental Systems Corporation (IncSys) and PowerData Corporation, focused on four advanced visualization aids developed at PNNL:

- Graphical Contingency Analysis

- Force Directed Graphs (FDG)

- Phasor State Estimator

- Mode Meter/Mode Shape

The scope of the present study includes initial human factors evaluations of these four visualization tools and development of proposed test plans to evaluate their utility in scenariobased experiments.

\subsection{Objectives}

The objectives of the study were to identify the most appropriate beneficiaries (users) of the visualizations (applicability), to describe the expected impact of the analyses/visualizations (impact), and to develop detailed plans for evaluating the effectiveness of operator tools and visualizations (evaluation plan). This includes plans and methods for human factors evaluation, experimental design and performance metrics. 


\subsection{Background}

The impact assessment focuses on the extent of facilitation of operator performance by the proposed analysis and visualization tools, examined within a human factors/performance evaluation framework based on a sophisticated cognitive approach to understanding and measuring performance using cognitive task analysis and naturalistic decision making concepts. The basis of this approach is an integrated decision making model (Greitzer, et al., 2009) that has been developed by adapting models specified a naturalistic decision making framework (Klein, 1993; Cohen, Freeman, \& Thompson, 1997). The Integrated Decision Model (IDM) describes decision making by articulating several cognitive processing stages, conceptualized using mediating variables such as mental models. The first stage is situation assessment, where mental models and cues from the environment are used to build an accurate story that describes the situation. The next stage is the determination of which action to take in order to positively affect the situation. Mental simulations, based on mental models, help predict the outcome of different actions and point towards an optimal decision. Finally, the new situation is assessed and a determination is made as to whether the situation is resolved or if the pattern needs repeating.

The primary purpose of this study was to conduct an initial assessment of the four visualization tools using a heuristic evaluation technique that identifies the expected operational utility and the most likely beneficiary of the tool. This analysis identified the user population (or "level of analysis") that is most appropriate for each tool-for example, whether the impact is on Reliability Coordinators, Transmission Operators or Planning Engineers, or perhaps higher level regulatory policy decision makers.

A second purpose of this study was to define a more indepth analysis of the visualization tools that may be conducted within specific experimental studies designed to measure the impact on decision making performance. Current practice in human factors evaluations of situation awareness and operational decision making performance typically involves pausing a scenario to ask the decision maker questions directed at identifying whether or not certain cues or concepts have been apprehended-e.g., the Situation Awareness Global Assessment Technique, or SAGAT (Endsley 1995). Our proposed experimental assessment method seeks to complement this practice by attempting to examine the operator's use of requisite mental models and associated mediating variables by defining observable responses as proxies for these variables. The proposed experiments will compare performance of an experimental group and a control gourp using a simulated scenario in which the experimental group has access to the visualization tool(s) and the control group does not have use of the tool(s). Participants will be power system professionals currently employed as a transmission operator, balancing operator, reliability coordinator, or a combination of the three roles.

\subsection{Approach}

A human factors framework based on a Recognition-Primed Decision Model (Klein, 1993) provides a theoretical basis for the analysis. The operator tools and visualizations are assessed with respect to possible applicability to normal, emergency and restorative system operations. The effort includes specification of experimental scenarios, variables and performance 
measures to test the effectiveness of each method or tool, using experimental design approaches that may include both off-line study tools and real-time grid simulators running within the Electricity Infrastructure Operations Center (EIOC).

One goal of the study is to document the manner in which each visualization tool can reinforce useful known mental models as well as introduces new mental models for power system operator decision making. This is done to inform the analysis and specification of how or whether application of the tools supports real time operation by Reliability Coordinators, Balancing Authorities and Transmission Operators. A secondary focus is on applicability to and impact on higher-level decision makers, such as regulatory policy makers.

Another goal of the study is to develop a concept and experimental design to evaluate the effectiveness of the visualization tools. The approach is to define experimental variables and performance measures, describe simulation scenarios and specify either static manipulations or simulation-based manipulations within a proposed experimental paradigm to be conducted within the PNNL EIOC.

\section{$1.4 \quad$ Expected Results}

Expected products of this research include:

- Documentation of the manner in which each visualization tool can reinforce useful known mental models, and suggest/define new mental models for power system operator decision making based on the visualization tools.

- Identification of/recommendations on appropriate test/evaluation requirements for each of the four visualization tools listed above, based on conversations with PNNL project staff.

- Identification/recommendations on the design of experimental studies or human factors "heuristic" evaluations to evaluate the potential impact/effectiveness of these tools.

- Identification/recommendations on possible simulation-based studies that could be performed, along with operating objectives and associated performance measures, for evaluating performance using the visualization tools in a controlled, scenario-based experiment that may be conducted within the PNNL EIOC.

- Assessment of the expected impact of the tools on system performance: the primary focus is on the use of the tools by Reliability Coordinators, Balancing Authorities and Transmission Operators; a secondary focus will be on applications by policy makers.

The expected outcome of the proposed experiment is that the nature and extent of the impact of power grid visualization tools developed by PNNL will be assessed. Specifically, according to the IDM and mental models identified with the tools, the experiments will seek to determine if the visualizations trigger appropriate mental models needed by system operators to understand the state of the system in real time and promote effective and timely actions. The expectation is that the framework and experimental method specified in the proposed study will be useful for identifying performance impacts and utility of power grid analysis and visualization tools developed not only by PNNL but also by other R\&D groups, with evaluations that may be conducted on behalf of industry and DOE stakeholders. Ultimately, it is hoped that the human factors and test/evaluation methodology, applied within the PNNL EIOC, will lead to the 
deployment of more effective tools and visualizations that will ultimately improve the performance of power grid operators, supervisory personnel, and regulatory policy makers through enhanced situation awareness and cognitive decision support, and ultimately create more reliable and secure electric power grid interconnection and operations. 


\section{An Integrated Decision Model}

The goal of the developed visualization tools for critical decision making is to provide the system operators with tools that will trigger mental models and simulations that will make it possible for the operator to assess the situation and come up with an action script that will resolve or improve the current electrical system state.

This document will describe how experiments can be developed that test if the right mental models are accessed and if that leads to better operator decision making. As a theoretical background this report uses an integrated decision model which integrates concepts of situation awareness (Endsley, 1997), recognition-primed decision making (RPD) (Klein, 1993), and metacognition (Cohen et al., 1997) into one model.

Figure 2-1 is a depiction of an integrated naturalistic decision making model-the Integrated Decision Model (IDM) - which proved useful for analyzing how expert power grid operators make decisions. It can be seen that the IDM is strongly influenced by insights of Weick (1995) on sensemaking concepts that have been applied to power grid operations (Greitzer et al., 2008), and largely based on the RPD model; it incorporates the meta-cognitive/critique portion of the R/M model by invoking additional mental models and mental simulations in the pattern recognition process.

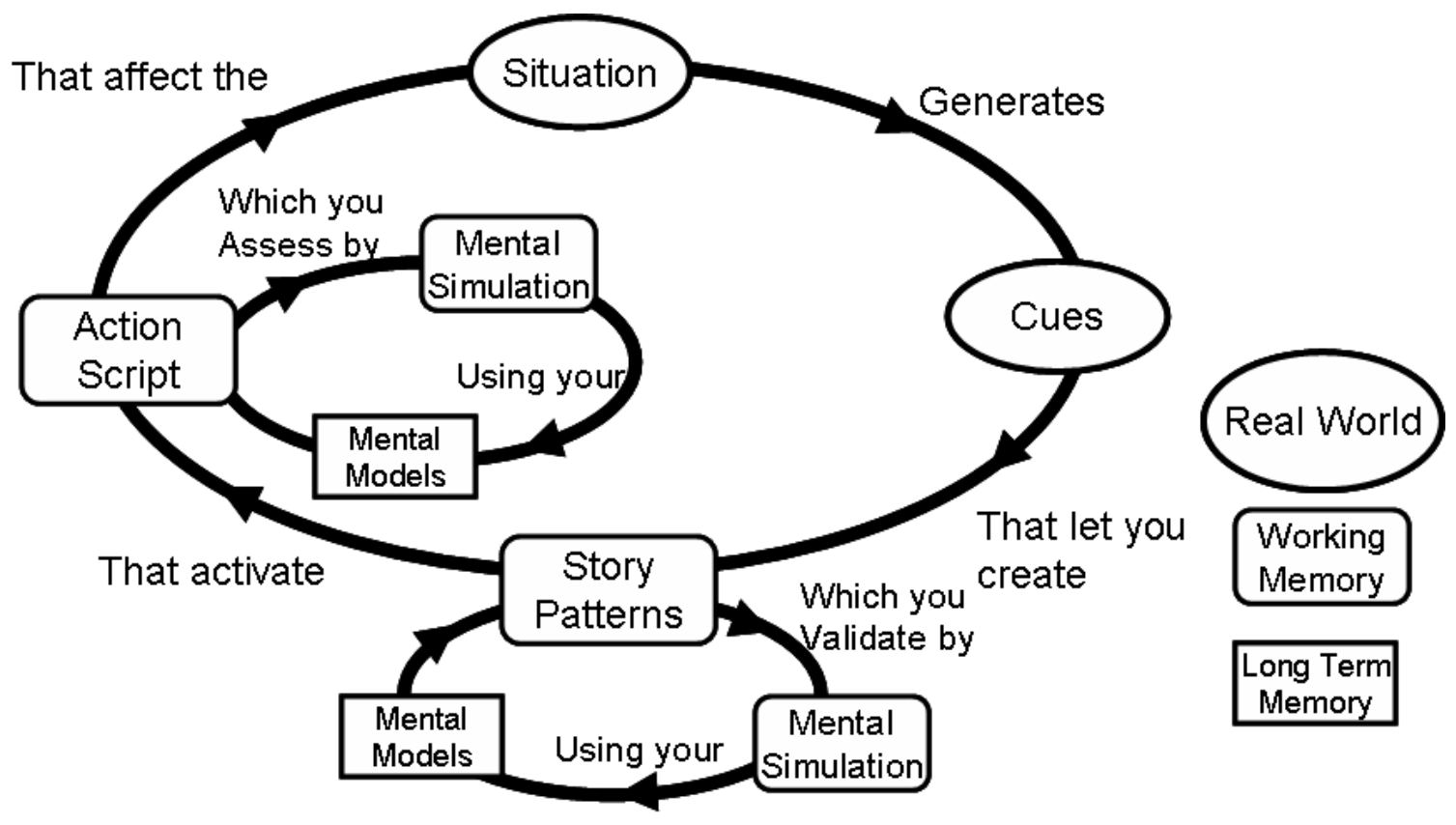

Figure 2-1. GRid-operations Integrated Decisionmaking (GRID) model 
The initial processing of cues and patterns may be modulated by a critiquing process (using mental models and simulations) that occurs early in the recognition-primed process of situation assessment. Additional mental simulation processes occur following selection of a course of action (action script), as the decision maker examines or tests whether the proposed response action work as anticipated. The main advantage of this characterization is that it acknowledges the role of mental models in the situation awareness component of decision making as well as in response selection.

Concepts of cues, mental models, mental simulations, patterns, stories and action scripts are used at all phases of the effort for evaluating the visualization tools. See Appendix A for a more detailed discussion of the IDMI and use of these constructs. 


\section{Potential benefits of the Visualization Tools}

This section documents the results of heuristic evaluations of the expected impact of the tools on system performance. Heuristic evaluation (Nielsen and Molich, 1990; Nielsen, 1994) is a "usability inspection method" in which a user interface design is inspected systematically based on usability criteria or user-computer interface guidelines. The goal of heuristic evaluation is to find the usability problems in the design so that they can be addressed as part of an iterative design process. In a heuristic evaluation, a small number of evaluators examine the interface and judge its compliance with recognized criteria (the "heuristics"). The application of heuristic evaluation in the present research is less concerned with usability and user-computer interface design issues per se, and more focused on application of cognitive task analysis and naturalistic decision making principles to identify potential for the visualization tools under study to impact the decision process.

The primary focus of the analysis is on use of the tools by Reliability Coordinators, Balancing Authorities and Transmission Operators; a secondary focus is on applications by policy makers. Of interest is the manner in which each visualization tool may reinforce useful known mental models, and the possible utility of new mental models for power system operator decision making that are motivated by the visualization tools. The integrated decision model described in section 2 (and Appendix A) provides a framework that facilitates the identification of potential benefits of the visualization tools.

Questions to be answered about the four tools:

- Applicability: To what level of decision maker does it apply (/who is it for)?

- Impact: What is the benefit/impact on performance and decision making?

\subsection{Geographic Contingency Analysis}

\subsubsection{Description of Tool}

Current Contingency Analysis programs provide a tabular summary of the violations for each harmful contingency. Violations can consist of line and transformer MVA violations, interface MW violations, bus voltage violations, and node pair angle separation violations.

The geographic contingency analysis tool developed by PNNL will provide a visualization of the most severe contingencies. The tool can provide a wide-area view that shows large geographical areas of the electric system (e.g. WECC). For the wide-area view, a map generated with Google Earth will be used to show which contingencies have the most severe effects on system conditions at any particular point in time.

The tool can also be applied for local systems to show the most severe contingencies on a local system map. The effects of each contingency can be shown to the operator. 
In this tool different layers can be applied. Operators can choose to show one contingency at a time or all the contingencies at the same time. The first option will be helpful for local systems in that they can see the most severe contingency first and take preventative action. The latter will be helpful to get a better picture of the problem areas that are affecting the whole WECC system.

The contingencies shown on the maps will be ranked starting with most severe to least severe. This ranking will become apparent as the color on the map changes to represent severity.

\subsubsection{Applicability}

This tool can be used to benefit Reliability Coordinators and Transmission Operators:

- Reliability Coordinators can use this tool to get a quick overview on the status of the system and which areas are causing a potential threat. The large area that Reliability Coordinators have to monitor make it hard to sort through a tabular display that lists 10's to 100's of contingencies. The Graphical Contingency Analysis will help Reliability Coordinators in being able to assess the system status quicker and get a sense of where the problem areas are. By showing the Reliability Coordinator the limitations and weak spots in a future state of system, it will lead to better situational awareness and decision making if preventive measures are performed.

- Transmission Operators can use this tool to get a quick overview of their local system and see which areas are causing potential threats as well as being able to assess the influence of neighboring systems on their system status. With this the Transmission Operator might be able to more quickly recognize a potential threat to the system and start preventative actions. If the transmission operator assesses that the problem is not originating in his/her local network, then he/she will still achieve a higher situational awareness on par with the Reliability Coordinator, which in turn should affect the group decision making ability and speed.

\subsubsection{Impact}

General Impact and Rationale: System operators tend to have a very good understanding of the system state after a single contingency. However, when multiple outages occur, operators are far less prepared to handle the specific situation, especially if this particular set of outages has never occurred before. The Geographic Contingency Analysis tool is therefore expected to positively impact situation awareness especially when the operator is in an unfamiliar situation that involves several outages simultaneously. It is expected that the Geographic Contingency Analysis Tool will help the operator more quickly recognize a contingency or emergency state and more quickly identify effective preventative measures.

The geographic contingency analysis tool will provide Reliability Coordinators a more effective, quick overview of the system status and help them more effectively direct utilities to perform preventative actions. We suspect that this will help the Reliability Coordinator maintain system reliability. He/she will also better understand where the problem areas are and identify where to direct preventative actions. Because of the large scope of the WECC system, we expect that the tool will provide better situational awareness that will enable the Reliability Coordinator to 
respond more quickly to possible contingencies, which contributes to improved system reliability.

The geographic contingency analysis tool will improve the situation awareness of the Transmission Operator and provide a more effective, quick overview of the status of his/her local system. By providing a ranking of the different contingencies, the geographic contingency analysis tool will help focus the Transmission Operator's attention on the most severe contingency and properly prioritize the preventative actions. Because of the wide-area view that this tool can provide, a Transmission Operator can also get a better sense of the impact that neighboring systems have on his/her own system and how the different systems react to each other. Thus, overall it should improve the Transmission Operator's speed in assessing the status of the system, taking preventative actions and increasing his/her situational awareness. Outages and other severe contingencies can be prevented more effectively with this tool.

A summary of applicability and impact assessment for the Geographic Contingency Analysis tool is shown in Table 3-1.

Table 3-1. Applicability and Impact Assessment of Geographic Contingency Analysis Tool

\begin{tabular}{|l|l|l|}
\hline Applicability & How it is done today... & Impact/benefit of the tool \\
\hline Reliability Coordinator & $\begin{array}{l}\text { Must review tabular summary of } \\
\text { alarms and violations in which a long } \\
\text { list of entries must be examined to } \\
\text { understand the scope and nature of } \\
\text { the problem. This is a tedious, labor- } \\
\text { intensive task with minimal support for } \\
\text { situation awareness. No wide-area } \\
\text { view of the system is available in } \\
\text { standard displays. }\end{array}$ & $\begin{array}{l}\text { Quicker and more comprehensive } \\
\text { situation awareness, identification of } \\
\text { weak spots and mitigation options. }\end{array}$ \\
\hline Transmission Operator & Same as above & $\begin{array}{l}\text { Quicker and more comprehensive } \\
\text { situation awareness, identification of } \\
\text { weak spots and mitigation options. }\end{array}$ \\
\hline
\end{tabular}

\subsection{Force Directed Graphs}

\subsubsection{Description of Tool}

Currently system maps are shown geographically. The Force Directed Graphs visualization tool developed by PNNL will be able to represent a power system as a force directed graph that shows electrical distance instead of geographical distance. The benefit of this tool is that operators can more easily determine system condition and stability.

The Force Directed Graphs have value for both planning as well as monitoring of the electric system. The tool uses voltage magnitude, voltage angle, real power injection, reactive power 
injection, real load, reactive load etc. to weigh the nodes and resistance, reactance, impedance, real power flow, reactive power flow, real losses, reactive losses etc. to weigh links (lines). The weighting of nodes and links on force directed graphs determine an "electrical distance" between power system components.

\subsubsection{Applicability}

This tool will provide benefits to Reliability Coordinators, Transmission Operators, and System Planners:

- Reliability Coordinators can use this tool to get a quick overview of the system condition using a wide area view. The weak spots will show up in the Force Directed Graph by showing a limited number of lines and a big distance between these lines. This will show a spot where the system is likely to split up and become different islands.

- Transmission Operators can use this tool to get a quick overview of the local system and its weak spots as well as a wide area view. The Transmission Operator will get an idea of where the weak spots in the system are and what the cause might be.

- System Planners might be able to use this tool as a forecasting tool. They would take historical cases and plan transmission and generation installations based on the weaknesses shown. The visual representation can provide a quick overview of the system and a useful visual aid in explaining plans to support teams.

\subsubsection{Impact}

General Impact and Rationale: Force Directed Graphs (FDG) can provide a visualization of power system status in terms of electrical distances rather than merely the geographic topology of the grid. When topological changes occur in a system, or even power flow changes, the electrical distance between power system objects can change dramatically. In geographically based maps, these changes are lost in the static nature of the geographic graph. FDGs can present a visualization of the strengths and weaknesses of the system and vulnerability to transient shocks. The type of situation in which the advantage of FDGs is particularly evident is when the system is in a state that is vulnerable to transient instability.

A summary of applicability and impact assessment for the Force Directed Graph tool is shown in Table 3-2.

This tool will help Reliability Coordinators by providing them with a quick system overview that will show where the weak spots are. This will lead to a better situational awareness by the Reliability Coordinator and more time for him/her to assess the situation and take the right preventative action (e.g. prevent islanding and line overloads). We assume that this will lead to fewer mistakes and a more reliable system.

This tool will help increase the situational awareness of Transmission Operators by giving them a way to view the whole WECC system and its weak spots. It will help in determine where their own local system is weakest and how this might be affected by their neighboring systems. This tool will help Transmission Operators in a quicker assessment of system conditions and therefore help prevent islanding and line overloads. By a quicker assessment of system 
conditions more time can be spend on making the right decision to alleviate the current condition and therefore there is more opportunity to assess the different options and take the right action. We assume that this will lead to fewer errors and a more reliable system.

Table 3-2. Applicability and Impact Assessment of the Force-Directed Graphs Tool

\begin{tabular}{|c|c|c|}
\hline Applicability & How it is done today... & Impact/benefit of the tool \\
\hline Reliability Coordinator & $\begin{array}{l}\text { System maps portray the electric } \\
\text { power grid topology. Little or no } \\
\text { status information is conveyed on } \\
\text { such maps, and no relationships or } \\
\text { dependencies are identified. There is } \\
\text { no current visualization that provides } \\
\text { the status and situation awareness } \\
\text { addressed by force-directed graph. }\end{array}$ & $\begin{array}{l}\text { Provides a quick overview of the } \\
\text { system condition using a wide area } \\
\text { view. More quickly and easily identifies } \\
\text { weak spots (where system is more } \\
\text { likely to split up into islands) evident by } \\
\text { showing a limited number of lines and } \\
\text { a big distance between these lines. }\end{array}$ \\
\hline Transmission Operator & $\begin{array}{l}\text { System maps portray the electric } \\
\text { power grid topology. Little or no } \\
\text { status information is conveyed on } \\
\text { such maps, and no relationships or } \\
\text { dependencies are identified. There is } \\
\text { no current visualization that provides } \\
\text { the status and situation awareness } \\
\text { addressed by force-directed graph. }\end{array}$ & $\begin{array}{l}\text { Improves situation awareness by } \\
\text { providing a more comprehensive view } \\
\text { of the system and its weak spots. } \\
\text { Helps to prevent islanding and line } \\
\text { overloads. Faster situation awareness } \\
\text { allows more time for decision making } \\
\text { (analysis of courses of action). Can } \\
\text { more easily determine system stability. }\end{array}$ \\
\hline System Planner & $\begin{array}{l}\text { System maps portray the electric } \\
\text { power grid topology. Little or no } \\
\text { status information is conveyed on } \\
\text { such maps, and no relationships or } \\
\text { dependencies are identified. There is } \\
\text { no current visualization that provides } \\
\text { the status and situation awareness } \\
\text { addressed by force-directed graph. }\end{array}$ & $\begin{array}{l}\text { May use this tool for forecasting by } \\
\text { taking historical cases and using the } \\
\text { visualization of weaknesses to plan } \\
\text { transmission and generation. } \\
\text { Facilitates examination of possible } \\
\text { longer term network changes to } \\
\text { address problems. The visualization } \\
\text { provides faster situation awareness } \\
\text { and facilitates explaining plans to } \\
\text { support teams. }\end{array}$ \\
\hline
\end{tabular}

Planners will benefit from this tool in that it will give them a quick overview of where the trouble spots are and how those can be resolved by longer term network changes.

\subsection{Phasor State Estimator}

\subsubsection{Description of Tool}

The Phasor State Estimator (PSE) uses Phasor Measurement Units (PMUs) in the field to gather power system data. This data includes phasor measurements, which can be recorded at 
rates of thirty times a second. Moreover, because the data are integrated with GPS units, accurate time stamping of each measurement is possible.

This new tool developed by PNNL offers a new way to bring data into the control room that are more reliable, and that makes it easier to identify incorrect data. Another advantage of using PMU data-once it is deployed and in wide use across the system —is that the PMU data can provide operators with a check of SCADA data.

\subsubsection{Applicability}

This tool will benefit Reliability Coordinators and Transmission Operators:

- Reliability Coordinators and Transmission Operators can use the Phasor State Estimator to directly check for bad data. They can use the Phasor State Estimator to complement existing applications that require state estimation or run new applications altogether. This is expected to increase the overall situation awareness for these roles.

In addition, this tool can be used as the foundation for a number of different applications:

- Contingency Analysis

- Mode Meter/Mode Shape

- Force Directed Graphs

- Smart islanding schemes

- Wide area power flow views

\subsubsection{Impact}

General Impact and Rationale: The Phasor State Estimator has the potential to be beneficial in many different ways. This tool has value not only to human operators but also to a variety of power system applications such as contingency analysis, protection systems, and bad data determination. The ideal situation in which to demonstrate the impact of the Phasor State Estimator is a scenario that involves bad data; the expected impact of the visualization tool would be to facilitate tracking down and recognition of bad data and the resultant improvement in the operation of the system.

A summary of applicability and impact assessment for the Phasor State Estimator tool is shown in Table 3-3.

In major outages such as the New York blackouts in 1965 and 1977 and the Northeastern blackout in 2003, the operators were under the impression for an extended period of time that certain lines were in service, when they were actually out of service. (See, for example, U.S.Canada Power System Outage Task Force, 2004). The Phasor State Estimator (PSE) has the potential to provide a means for detecting and isolating network topology errors. 
Table 3-3. Applicability and Impact Assessment for the Phasor State Estimator

\begin{tabular}{|c|c|c|}
\hline Applicability & How it is done today... & Impact/benefit of the tool \\
\hline Reliability Coordinator & $\begin{array}{l}\text { Some electric power utilities capture } \\
\text { PMU data, but generally they do not } \\
\text { take advantage of the exceptional } \\
\text { data rate and predictive power of } \\
\text { advanced analyses of these data. } \\
\text { Without such analyses and } \\
\text { visualizations, decision makers and } \\
\text { operators are deprived of wide-area } \\
\text { views and more precise evaluations } \\
\text { of the state of the grid system. }\end{array}$ & $\begin{array}{l}\text { - Facilitates detection and isolation } \\
\text { of network topology errors } \\
\text { - } \quad \text { Facilitates identification of bad } \\
\text { data. } \\
\text { - Can provide a check of SCADA } \\
\text { data } \\
\text { Can provide a foundation for } \\
\text { several other tools: Contingency } \\
\text { Analysis, Mode Meter/Mode } \\
\text { Shape, Force Directed Graphs, } \\
\text { Smart islanding schemes, Wide } \\
\text { area power flow views. }\end{array}$ \\
\hline Transmission Operator & Same as above & Same as above \\
\hline
\end{tabular}

\subsection{Mode Meter \& Mode Shapes}

\subsubsection{Description of Tool}

The Mode Meter and Mode Shapes tool, developed by PNNL, gives operators a way to monitor oscillations and dynamic stability among groups of generators over a wide area.

Currently system operators do not have a tool that will show oscillations between generators. The only way for an operator to see this is by noticing large swings in MW transferred back and forth between generators. In a real-time situation the true cause of flow changes may not be clear. The Mode Meter tool and associated visualization can show oscillations of generators and the damping factor that is needed to diminish these oscillations. It shows the operator which generators are oscillating at a certain mode and it indicates how much these oscillations are damped. The Mode Meter shows the limit where oscillations will be damped out-where there will not be any problems for the operator-or when generators will cross this limit and the oscillations will become problematic.

The Mode Shapes tool works with the Mode Meter not only to determine the frequency at which the generators are oscillating and the damping factor, but also the geographical locations of the oscillating generators. This will help operators determine which generators are participating in the oscillations and what actions are needed to solve the problem.

\subsubsection{Applicability}

This tool will be very useful for Generator Operators, Balancing Authorities, Transmission Operators, Reliability Coordinators and Planning Engineers. 
- Generator Operators can use this tool to improve situational awareness. This tool will give operators an explanation of why a generator is swinging and it will provide an opportunity to take proactive action and contact the right authorities before the oscillations turn in to a dangerous situation. Group decision making ability will be enhanced.

- Balancing Authorities will see the large MW swings on the systems and can use this tool to increase their situation awareness and take proactive action. Making this tool available to Balancing Authorities will provide a better understanding of the system state, how one's own area is involved, and what actions need to be taken. Group decision making ability will be enhanced.

- Transmission Operators will benefit from increased situation awareness resulting from use of the tool. The Transmission Operator will notice the MW swings on the system; the Mode Meter and Mode Shapes displays will provide a better understanding of the swings, which generators are causing the swings, and how to resolve this problem. It may provide an explanation of why the network is experiencing periodic overloads. Group decision making ability will be enhanced.

- Reliability Coordinators are responsible for the reliability of the Bulk Electric System. The Mode Meter/Mode Shapes tool has a direct application in helping the Reliability Coordinator achieve better situation awareness; it will help the Reliability Coordinator see the large swings in MW on the systems. The Mode Meter and Mode Shapes provide the Reliability Coordinator information on where system swings are occuring, which generators are participating in the oscillations, and what actions are necessary to prevent threats to the reliability of the system. The Mode Meter/Mode Shapes tool is therefore expected to facilitate the Reliability Coordinator's ability to direct actions to reduce dynamic instability.

- Planning Engineers will benefit from use of the Mode Meter/Mode Shapes tool through information provided about data on generators that regularly swing against each other. With this information, Planning Engineers can make longer term adjustments to the grid to limit oscillations between generators.

\subsubsection{Impact}

General Impact and Rationale: The Mode Meter and Mode Shape tools provide visualization to an area of power systems that is traditionally devoid of much real-time monitoring: dynamic stability. In practice, with dynamic instability, most operators are completely in the dark, with nothing more than a cryptic telephone call from a generator operator, if they're fortunate. This may or may not help in the assessment of the problem. Thus the Mode Meter and Mode Shape Tools would be expected to greatly facilitate performance under conditions when the system becomes negatively damped, which has the ultimate effect of increasing dynamic instability that will yield islanding unless appropriate action is taken.

A summary of applicability and impact assessment for the Mode Meter/Mode Shapes tool is shown in Table 3-4. 
Table 3-4. Applicability and Impact Assessment for the Mode Meter/Mode Shapes Tool

\begin{tabular}{|c|c|c|}
\hline Applicability & How it is done today... & Impact/benefit of the tool \\
\hline Reliability Coordinator & $\begin{array}{l}\text { Most operators are completely in the } \\
\text { dark under conditions of dynamic } \\
\text { instability }\end{array}$ & $\begin{array}{l}\text { - Enhances situation awareness } \\
\text { - } \text { Provides an explanation of why a } \\
\text { - Provides opportunity to take } \\
\text { proactive action before the } \\
\text { oscillations turn in to a dangerous } \\
\text { situation. }\end{array}$ \\
\hline Transmission Operator & $\begin{array}{l}\text { Most operators are completely in the } \\
\text { dark under conditions of dynamic } \\
\text { instability }\end{array}$ & $\begin{array}{l}\text { - } \quad \text { Enhances situation awareness } \\
\text { - } \quad \text { Provides an explanation of why a } \\
\text { - } \quad \text { Provides opportunity to take } \\
\text { proactive action before the } \\
\text { oscillations turn in to a dangerous } \\
\text { situation. }\end{array}$ \\
\hline Generator Operator & $\begin{array}{l}\text { Most operators are completely in the } \\
\text { dark under conditions of dynamic } \\
\text { instability }\end{array}$ & $\begin{array}{l}\text { Provides an explanation of why a } \\
\text { generator is swinging } \\
\text { Provides opportunity to take } \\
\text { proactive action before the } \\
\text { oscillations turn in to a dangerous } \\
\text { situation. } \\
\text { - Enhances group decision making. }\end{array}$ \\
\hline Balancing Authority & $\begin{array}{l}\text { Most operators are completely in the } \\
\text { dark under conditions of dynamic } \\
\text { instability }\end{array}$ & $\begin{array}{l}\text { Helps to see the large MW swings } \\
\text { on the systems and increase } \\
\text { situation awareness } \\
\text { - Provides better understanding of } \\
\text { the system state, how one's own } \\
\text { area is involved, and what actions } \\
\text { need to be taken. } \\
\text { - Enhances group decision making. }\end{array}$ \\
\hline Planning Engineer & $\begin{array}{l}\text { Most operators are completely in the } \\
\text { dark under conditions of dynamic } \\
\text { instability }\end{array}$ & $\begin{array}{l}\text { - Provides visibility about generators } \\
\text { that regularly swing against each } \\
\text { other. } \\
\text { - Facilitates longer term adjustments } \\
\text { to the grid to limit oscillations } \\
\text { between generators. }\end{array}$ \\
\hline
\end{tabular}

Generator Operators will gain situation awareness from this tool, which will help them make the right decisions in a more timely way. If oscillations are not damped quickly, they will grow and 
become unstable, putting the reliability of the system at risk. By giving the Generator Operator a tool to assess the situation and identify actions that must be taken to resolve the problem, the Mode Meter/Mode Shape tool will will increase system reliability.

The Balancing Authorities gain from this tool by increased situation awareness. They can see what causes the swings in MW and take proactive actions in a timelier manner.

The performance of Transmission Operators will improve because the tool helps them assess the source of power flow variations and potential problems with such flows. This information will increase situation awareness and enhances decision making.

The Reliability Coordinator will benefit from increased situation awareness and effectiveness in directing the right entities to take the right actions. By knowing the cause of the oscillations, the right decisions can be made more quickly; this improves system reliability. In addition, this capability will help prevent Islanding and separations because of the more timely and effective actions. 


\section{Simulation and Test Environment}

\subsection{Objective}

This section addresses the identification and recommendations of appropriate test requirements for each of the four visualization tools (Geographic Visualization of Contingency Analysis, Force Directed Visualization, Phasor State Estimator and Mode Meter/Mode Shapes).

\subsection{Conceptual Model}

As diagrammed in Figure 4-1, the experiments will test the relationship between the visualization tools and performance. To derive expectations about the effects of the tools on performance, we "exercise" the IDM to identify key mental models that the tools are expected to trigger; to the extent that the correct mental models are triggered and understood, the visualization tool is expected to positively impact performance. The main impacts of applying the correct mental models under these circumstances are more timely and accurate decision making.

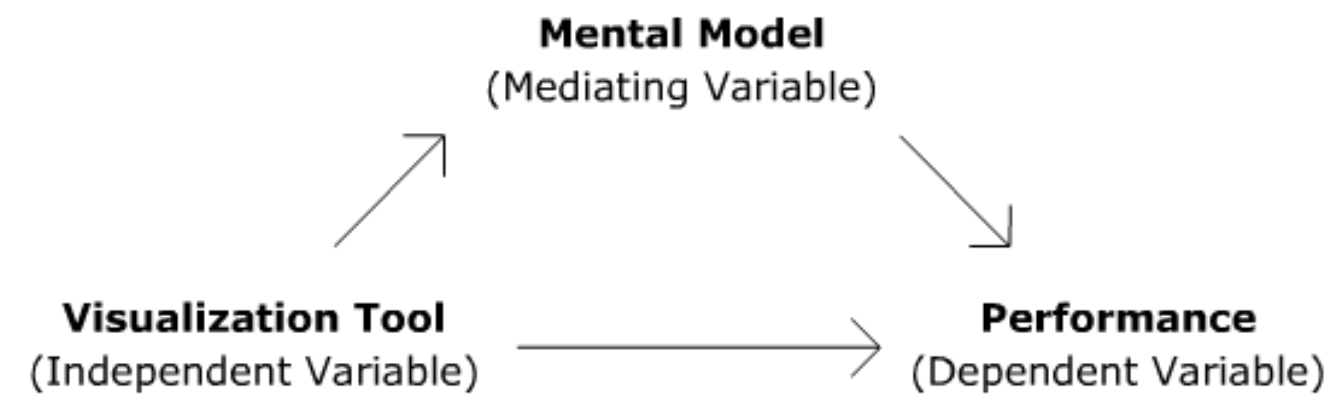

Figure 4-1: Conceptual Model Showing Relationship Between Visualization Tools and Performance in Experiments

\subsection{Pretest-Posttest Nonequivalent Groups Quasi-Experimental Design}

As outlined in Table 4-1, the proposed experiments will compare performance of an experimental group that has access to the visualization tool(s) in a simulated scenario with a control group that does not have use of the tool(s). The experiment thus comprises two groups of six participants each $(\mathrm{N}=12) .{ }^{1}$ Participants will ideally be power system professionals currently employed as a transmission operator, balancing operator, reliability coordinator, or a combination of the three roles; if necessary we will employ non-professionals (research staff, etc.) in initial demonstration studies. Both groups will have to complete a pre-test survey to assess their initial level of performance and to control for variation between the groups in knowledge, comfort level in broad operation areas, and work experience. Performance of the participants in both groups will be evaluated by Subject Matter Experts.

\footnotetext{
${ }^{1}$ The experiment described is referred to as a "quasi pre-test post-test non-equivalent group experiment" (Campbell and Stanley, 1966).
} 
Table 4-1: Experimental Design

\begin{tabular}{|l|l|l|l|}
\hline Group & Observation & Treatment & Observation \\
\hline Experimental group & Pretest Survey & Visualization Tool & Performance Evaluation \\
\hline Control Group & Pretest Survey & & Performance Evaluation \\
\hline
\end{tabular}

\subsection{General Information on Experiment Design}

In accordance with the IDM, this experiment assumes that all participants have stored in their long term memory the necessary mental models to successfully operate a power system. To control for differing levels of expertise of the participants, namely whether they have knowledge of the mental models, a half-day pre-drill class will be given to all participants covering the full list of mental models that are necessarily accessed during the scenarios.

A NERC ILA (Individual Learning Activity) will be submitted and accepted by NERC prior to the experiment. Due to the limited availability of test participants, the possibility of offering continuing education credits (CEHs) for all or part of the experiment for participation greatly improves the chances of attracting candidates.

All participants will run individual-based experiments on a single console in a shared session of PowerSimulator with the facilitator. The facilitator will have access to the same session to capture the session information, and may play power system roles when necessary. No spectators besides the facilitator and assistants are permitted. Running the experiments on PowerSimulator will create a realistic environment for the operator with the opportunity to take control actions and run the model as a real power system. This will make it possible to test the visualization tools in a situation very close to reality.

The computer system will consist of a laptop, a second monitor, and a mouse will be available for the participants. The computer system will be prepared prior to the test with the latest version of java and loaded with Mozilla Firefox 3.0 to run the simulations. Visualization tools will be preloaded with necessary materials on the computer system. A telephone system will be provided which will allow the student to interact with the facilitator.

The facilitator will control a second console (a laptop) virtually which is placed next to the first console. The second console will act only as a view for the participant. This computer system will play any alarms (since these are not currently enabled in PowerSimulator) and special movie clips or show static shots of the visualization tools where applicable.

Each scenario will utilize only one of the visualization tools. Isolating the visualization tools is necessary to determine the impact each one has on performance. A future study could be prepared to evaluate performance based on human factors by combining all four advanced visualization tools. 
Prior to the scenarios, all participants will be given a general briefing on system conditions and if there are any specific objectives. They will be given 5 minutes to consider this information, but have no access to the simulator or visualization tools until this interval is complete. They may opt to start before 5 minutes if comfortable. General system conditions can include current load, expected weather considerations, interchange schedules that may be active, current line outages, synchroscope operation and generator positions and modes. All scenarios will be run assuming inverse time current relays are active on 5 minute and 15 minute delays depending on extent of overload.

\subsection{Pre-Experiment Class}

The pre-experiment class has two objectives:

1) Review the mental models that are necessarily accessed during the experiment

2) Review the PowerSimulator tool interactions and PALCO system

It is important to review the appropriate mental models because some participants may have no experience or awareness of mental models and related concepts, and they may not be familiar with visualization tools that are in the study. For example, some participants may be unfamiliar with analyses or visualizations of oscillations.

Review of the PALCO system will include load centers, generation sources, line MVA limits, interties with external system, reactive resources. Also provided are explanations of roles in shared simulations (i.e. transmission operator, reliability coordinator, balancing authority, generator operator).

Review of the PowerSimulator tool will include: navigation, operating breakers, operating reactive resources, adjusting transformer taps, adjusting generator set points and modes, enacting an interchange schedule, system monitoring functions, accessing the AGC Summary page, accessing the Generator MW controls page, review of simulator graphic conventions, removing/adding load and adjusting feeder percentages, OTS Violation tabular displays, etc.

The pre-experiment class will be conducted by a power systems expert and delivered to all participants.

\subsection{General Information on Performance Measures}

To determine the impact of the tools, we will compare performance of the experimental group with that of the control group on a set of performance measurements that will be determined for each of the scenarios. In addition to general performance measures such as timeliness and quality of decisions, other detailed measures will address the extent to which appropriate and key mental models are utilized; and the extent to which appropriate cues are recognized. Depending upon the nature and significance of the differences in performance between the experimental and control groups, conclusions may be derived about the effectiveness of the visualization tool in facilitating situation awareness and improving decision making. 
Specifically, a set of human factors performance measures has been established based on the Greitzer et al. (2009) IDM. For each visualization tool, performance measures are defined that correspond to different stages in the IDM:

Measure 1: Recognition of Situation

Measure 2: Recognition of Cues and Construction of Story

Measure 3: Determination of Control Actions (compare to: action scripts) that positively affect the scenario

Each measure will include a time element such as: How long from the start of the scenario does it take the participant to recognize there is a situation that may have a negative effect on power system operation? The time elements are measured relative to scenario start time until a major milestone.

Furthermore, each measure will have a qualitative element such as: Did the participant correctly identify the correct story? The qualitative element is vital to evaluating the contribution of human factors to performance for a given tool. Post-experiment review and interview will seek to determine which mental models from a pre-determined, and complete list were accessed (or not) by the participant in completion of milestones.

\subsection{Data Gathering Techniques}

To capture relevant information on the performance of the participants during the experiment, we will use the following data gathering techniques:

- Pre-drill survey

- Video and Audio capture for each experiment, focused on the participant

- Screen capture for each experiment - the console will be fitted with Snagit software to capture the screens and actions that the participant views and takes.

- Running explanation of actions and thoughts - the participant will be asked to explain their thoughts and actions out loud for the duration of the experiment.

- PowerSimulator log-messages - the PowerSimulator log will be captured and include all control actions taken with time stamps.

- Stopwatch - each experiment will record the time the participant takes in reaching each major milestone relative to the scenario start time. This information will be logged by the facilitator during the experiment (assuming it is available - otherwise log is updated after experiment).

- Post scenario interview - a human factors expert will conduct an interview immediately after the experiment. Questions will be carefully constructed as to not lead the participant in the correct answer, but instead will be clarifying and focused on determining which mental models were accessed, at what times, and why. The interview will be recorded ideally with video/audio, but at a minimum audio only.

- Post scenario review - a Subject Matter Expert will review the actions taken by participants to determine the validity of the actions. The Subject Matter Expert will evaluate the on whether the participant accessed mental models used in the performance measure based on the available data. 


\section{Design of Individual Experiments to Demonstrate Benefits}

The assessment of the visualization tools includes both a heuristic evaluation (results described in Section 3) and the design and conduct of an experimental study. A general description of the planned experiments was provided in Section 4. The purpose of the present section is to describe in more detail the planned experiments associated with the four visualization tools. We identify and recommend possible simulation-based studies that could be performed, along with operating objectives and associated performance measures, for evaluating performance using the visualization tools in a controlled, scenario-based experiment that may be conducted within the PNNL EIOC.

\subsection{Graphical Contingency Analysis (GCA)}

\subsubsection{Overview}

System operators generally have a very good understanding of the system state after a single contingency. When multiple outages occur, operators are far less prepared to handle the specific situation, especially if this particular set of outages has never occurred before. Therefore, this scenario seeks to put the operator (participant) into this "unfamiliar" area by introducing several outages in a storm scenario. The question becomes: How aware is the participant that there is an alert or emergency state, and how effective are the preventative measures that the participant takes to put the system in a more defensive position?

\begin{tabular}{|c|c|c|}
\hline \multirow[b]{2}{*}{ Tools } & Experimental Group & Control Group \\
\hline & $\begin{array}{l}\text { - } \text { GCA Visualization Tool } \\
\text { - } \quad \text { PowerSimulator }\end{array}$ & $\begin{array}{l}\text { - Tabular display of contingencies } \\
\text { - PowerSimulator }\end{array}$ \\
\hline Mental Models & \multicolumn{2}{|c|}{ 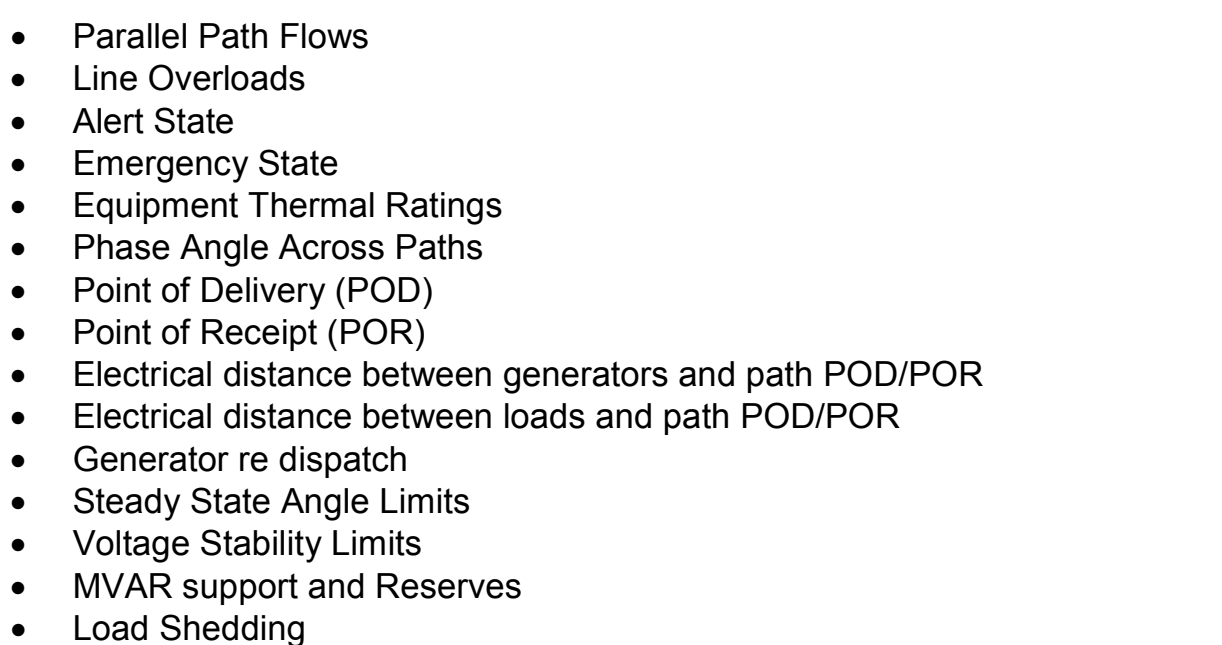 } \\
\hline
\end{tabular}




\begin{tabular}{|l|l|}
\hline Performance & - Correct mental models accessed? \\
Measures & $-\quad$ Time it took to build the right story \\
& - Right cues used to build the story? \\
& $-\quad$ Time it took to take (preventative) action \\
& $-\quad$ Was the right action taken? \\
\hline
\end{tabular}

\subsubsection{Exploring the Mediating Relationship}

\begin{tabular}{|c|c|c|}
\hline Mental Model & Trigger - Exp. Group & Trigger - Control Group \\
\hline Parallel Path Flows & $\begin{array}{l}\text { GCA shows how real and reactive flows } \\
\text { will be altered or redistributed to parallel } \\
\text { transmission paths in a potential } \\
\text { contingency due to the relationship of } \\
\text { line impedance and reactance and the } \\
\text { power flow solution. }\end{array}$ & $\begin{array}{l}\text { Tabular display of contingencies implies } \\
\text { that the power flow solution has changed } \\
\text { but it is not totally clear, especially in } \\
\text { instances of multiple outages, how the } \\
\text { line flows ultimately affect the power flow } \\
\text { solution. Judgments are set from an } \\
\text { intimate knowledge of the system. }\end{array}$ \\
\hline Line Overloads & $\begin{array}{l}\text { GCA shows potential line overloads if a } \\
\text { contingency occurs. Summarizes } \\
\text { overloads graphically through deeper red } \\
\text { tones. }\end{array}$ & $\begin{array}{l}\text { Using a tabular display, line overloads } \\
\text { are apparent, but less obvious. } \\
\text { Judgments for potential contingencies } \\
\text { are made based on intimate knowledge } \\
\text { of the system and probable trouble } \\
\text { spots. }\end{array}$ \\
\hline $\begin{array}{l}\text { Declaration of Alert } \\
\text { and Emergency } \\
\text { States }\end{array}$ & $\begin{array}{l}\text { GCA shows possible future states which } \\
\text { allows for better and faster declaration of } \\
\text { emergency or alert system condition }\end{array}$ & $\begin{array}{l}\text { More analysis on the impact is required. } \\
\text { Whereas the GCA summarizes all } \\
\text { contingencies with a deep red marking, } \\
\text { the tabular display requires the } \\
\text { participant to create a summation based } \\
\text { on a personal judgment call. }\end{array}$ \\
\hline $\begin{array}{l}\text { Generator Re- } \\
\text { Dispatch }\end{array}$ & $\begin{array}{l}\text { By showing the most critical system } \\
\text { contingencies, the GCA allows operators } \\
\text { to engage in generator re dispatch } \\
\text { sooner and more effectively. It shows } \\
\text { the most ideal locations to reduce and/or } \\
\text { increase generation. }\end{array}$ & $\begin{array}{l}\text { Must filter the results in the tabular } \\
\text { display, summate the entire results, and } \\
\text { then determine location of the most } \\
\text { suitable generators for re dispatch. This } \\
\text { process will take longer and introduce a } \\
\text { higher chance of human error. }\end{array}$ \\
\hline MVAR Support & $\begin{array}{l}\text { GCA shows potential voltage control } \\
\text { problems and allows for preventive } \\
\text { measures. Graphical characteristic } \\
\text { makes determining the location and } \\
\text { severity much easier. }\end{array}$ & $\begin{array}{l}\text { Must filter the results in tabular display, } \\
\text { summate the entire results, and then } \\
\text { determine location of the most suitable } \\
\text { voltage control equipment. This process } \\
\text { will take longer and introduce a higher } \\
\text { chance of human error. }\end{array}$ \\
\hline Load Shedding & $\begin{array}{l}\text { GCA shows the most viable locations for } \\
\text { load shedding should the biggest } \\
\text { contingencies occur. Graphical }\end{array}$ & $\begin{array}{l}\text { Must filter the results in tabular display, } \\
\text { summate the entire results, and then } \\
\text { determine location of the most suitable }\end{array}$ \\
\hline
\end{tabular}




\begin{tabular}{|l|l|l|}
\hline & $\begin{array}{l}\text { characteristic makes determining the } \\
\text { location and severity much easier. }\end{array}$ & $\begin{array}{l}\text { loads to shed. This process will take } \\
\text { longer and introduce a higher chance of } \\
\text { human error. }\end{array}$ \\
\hline $\begin{array}{l}\text { Equipment Thermal } \\
\text { Ratings }\end{array}$ & $\begin{array}{l}\text { GCA shows when equipment thermal } \\
\text { ratings have been exceeded graphically } \\
\text { through colorization for potential } \\
\text { contingencies. }\end{array}$ & $\begin{array}{l}\text { Tabular list shows thermal rating and } \\
\text { potential flows. Does not sum the } \\
\text { contingencies }\end{array}$ \\
\hline $\begin{array}{l}\text { Steady State Angle } \\
\text { Limits }\end{array}$ & $\begin{array}{l}\text { GCA reinforces steady state angle limits } \\
\text { may be exceeded with a potential } \\
\text { contingency graphically through } \\
\text { colorization. Sums up all steady state } \\
\text { angle violations for all contingencies with } \\
\text { dark colors. }\end{array}$ & $\begin{array}{l}\text { Tabular list shows the phase angle } \\
\text { following a contingency. Does not sum } \\
\text { the contingencies }\end{array}$ \\
\hline $\begin{array}{l}\text { Voltage Stability } \\
\text { Limits }\end{array}$ & $\begin{array}{l}\text { GCA shows voltage violations for } \\
\text { potential contingencies graphically } \\
\text { through colorization. Sums up all } \\
\text { voltage violations for all contingencies } \\
\text { with dark colors. }\end{array}$ & $\begin{array}{l}\text { Tabular list shows voltage violations } \\
\text { following a contingency. Does not sum } \\
\text { the contingencies }\end{array}$ \\
\hline
\end{tabular}

\subsection{Force Directed Graphs (FDG)}

\subsubsection{Overview}

Force Directed Graphs (FDG) can provide a visualization of power system status in terms of electrical distances rather than merely the geographic topology of the grid. When topological changes occur in a system, or even power flow changes, the electrical distance between power system objects can change dramatically. In geographically based maps, these changes are lost in the static nature of the geographic graph. FDGs can present a visualization of the strengths and weaknesses of the system and vulnerability to transient shocks. This scenario seeks to highlight the strengths of the FDG tool by putting the system in a state that is vulnerable to transient instability. The FDG will weigh phase angles on its nodes and impedance on its links.

\begin{tabular}{|l|l|l|}
\hline \multicolumn{2}{|l|}{ Force Directed Graphs } \\
\hline & Experimental Group & Control Group \\
\hline Tools & $\bullet \quad$ FDG Visualization & $\bullet \quad$ PowerSimulator \\
\hline Mental Models & $\bullet \quad$ PowerSimulator & \\
& $\bullet \quad$ Transient stability \\
& $\bullet \quad$ Generator Reserves \\
& $\bullet \quad$ Impact of Fault on System Stability \\
&
\end{tabular}




\begin{tabular}{|c|c|}
\hline & $\begin{array}{l}\text { - } \quad \text { Parallel path flows } \\
\text { - } \text { Generator Pole slipping } \\
\text { - } \quad \text { Coherent groups of generators } \\
\text { - } \text { System separation } \\
\text { - } \quad \text { Energy Functions } \\
\text { - } \quad \text { Potential Energy that can be absorbed by path } \\
\text { - } \quad \text { Interchange } \\
\text { - Line impedances } \\
\text { - } \quad \text { Voltage Angles }\end{array}$ \\
\hline $\begin{array}{l}\text { Performance } \\
\text { Measures }\end{array}$ & $\begin{array}{l}\text { - } \quad \text { Correct mental models accessed } \\
\text { - } \quad \text { Time it took to build the right story } \\
\text { - } \quad \text { Tight cues used to build the story } \\
\text { - } \quad \text { Was the right action taken? } \\
\text { - Is the situation resolved? }\end{array}$ \\
\hline
\end{tabular}

\subsubsection{Exploring the Mediating Relationship}

\begin{tabular}{|l|l|l|}
\hline Mental Model & Trigger - Exp. Group & Trigger - Control Group \\
\hline Electrical Distance & $\begin{array}{l}\text { FDG shows that the system has } \\
\text { drastically changed in terms of electrical } \\
\text { distance after an outage }\end{array}$ & $\begin{array}{l}\text { Geographic map doesn't show the } \\
\text { position of generators/loads based on } \\
\text { electrical distance. Assessment by } \\
\text { participant is prone to error in non- } \\
\text { normal system conditions. }\end{array}$ \\
\hline Transient Stability & $\begin{array}{l}\text { Indicates locations where transient } \\
\text { shocks can be potentially disastrous. }\end{array}$ & $\begin{array}{l}\text { Shows no indication graphically where } \\
\text { transients can be potentially disastrous. } \\
\text { This judgment is instead based on } \\
\text { comparison of phase angles between } \\
\text { generators, knowledge of protection } \\
\text { systems, and expectation of a fault. }\end{array}$ \\
\hline Generator Reserves & $\begin{array}{l}\text { Should generator re dispatch be } \\
\text { necessary to unload an overloaded line, } \\
\text { FDG will indicate the most suitable } \\
\text { generator to do so very clearly. What } \\
\text { generator reserves are available is } \\
\text { determined faster. }\end{array}$ & $\begin{array}{l}\text { Must determine the best generators for } \\
\text { re dispatch through a more intensive } \\
\text { manual analysis, which can be difficult in } \\
\text { abnormal system conditions. Thus } \\
\text { determination of the available generator } \\
\text { reserves for a generator re dispatch is } \\
\text { more difficult. }\end{array}$ \\
\hline $\begin{array}{l}\text { Impact of faults on } \\
\text { system stability }\end{array}$ & $\begin{array}{l}\text { The FDG graphically shows where faults } \\
\text { would be most devastating based on } \\
\text { sections of the map that are 'stringy'. }\end{array}$ & $\begin{array}{l}\text { Geographical maps show no indication } \\
\text { graphically where transients shocks } \\
\text { caused by faults can be potentially } \\
\text { disastrous. This judgment is instead } \\
\text { based on comparison of phase angles } \\
\text { between generators, knowledge of }\end{array}$ \\
\hline
\end{tabular}




\begin{tabular}{|c|c|c|}
\hline & & $\begin{array}{l}\text { protection systems, and expectation of a } \\
\text { fault. }\end{array}$ \\
\hline $\begin{array}{l}\text { Generator Re } \\
\text { dispatch }\end{array}$ & $\begin{array}{l}\text { The FDG graphically indicates which } \\
\text { generators are closest to sending or } \\
\text { receiving ends of lines. The location of } \\
\text { these generators in relation to a line is } \\
\text { vital for choosing the optimal generators. }\end{array}$ & $\begin{array}{l}\text { Generator re dispatch operations are } \\
\text { based on expectations formed from } \\
\text { manual analysis of parallel path flows. } \\
\text { This can become far more difficult if } \\
\text { system is in an abnormal condition. }\end{array}$ \\
\hline Parallel Path Flows & $\begin{array}{l}\text { The FDG shows a graphical relationship } \\
\text { of parallel path flows based on } \\
\text { impedance of transmission lines }\end{array}$ & $\begin{array}{l}\text { Determined from with past operational } \\
\text { studies, past experience, and analysis of } \\
\text { current system conditions. Can be } \\
\text { difficult to predict in abnormal conditions. }\end{array}$ \\
\hline System Separation & $\begin{array}{l}\text { The FDG graphically indicates where } \\
\text { likely system separation points are } \\
\text { located }\end{array}$ & $\begin{array}{l}\text { Not readily apparent. Manual analysis } \\
\text { and knowledge of operational studies is } \\
\text { necessary. Can be difficult to predict } \\
\text { and prevent in abnormal conditions. }\end{array}$ \\
\hline $\begin{array}{l}\text { Energy } \\
\text { Functions/Kinetic } \\
\text { Energy created by } \\
\text { fault/potential energy } \\
\text { that can be absorbed } \\
\text { by path }\end{array}$ & $\begin{array}{l}\text { For weak spots in the system, indicated } \\
\text { by longer link segments, the critical } \\
\text { energy value along a path becomes } \\
\text { hugely important in preventing system } \\
\text { separation due to transient (or other) } \\
\text { shocks. FDG shows the participant } \\
\text { where the most important areas to focus } \\
\text { on would be. }\end{array}$ & $\begin{array}{l}\text { Geographic maps give no indication on } \\
\text { where weak spots would be graphically. } \\
\text { This analysis must occur through } \\
\text { operational/planning studies and is } \\
\text { generally unavailable in real time. }\end{array}$ \\
\hline Interchange & $\begin{array}{l}\text { The FDG shows parallel path flows } \\
\text { clearly and graphically, which could } \\
\text { include a balancing area tie line. In } \\
\text { emergency and restoration conditions, } \\
\text { FDG can be especially valuable since } \\
\text { magnitude and distribution of flows going } \\
\text { along tie lines may not conform to the } \\
\text { usual patterns. }\end{array}$ & $\begin{array}{l}\text { Parallel path flows going across tie lines } \\
\text { indicated through dynamic text. }\end{array}$ \\
\hline Line Impedance & Shows line impedance graphically. & Shows line impedance textually \\
\hline Voltage Angles & Shows voltage angles graphically. & Shows voltage angles textually \\
\hline
\end{tabular}

\subsection{Phasor State Estimator}

\subsubsection{Overview}

The Phasor State Estimator (PSE) has the potential to be beneficial in many different ways. This tool has value not only to human operators but also to a variety of power system applications such as contingency analysis, protection systems, and bad data determination. The selected test scenario is a bad data detection scenario, which shows the difficulty in tracking down bad data and the potential impact on the operation of the system. 


\begin{tabular}{|c|c|c|}
\hline \multicolumn{3}{|c|}{ Phasor State Estimator } \\
\hline \multirow[b]{2}{*}{ Tools } & Experimental Group & Control Group \\
\hline & $\begin{array}{ll}\text { - } & \text { PSE Visualization } \\
\text { - } & \text { PowerSimulator }\end{array}$ & - PowerSimulator \\
\hline Mental Models & \multicolumn{2}{|c|}{$\begin{array}{l}\text { - } \quad \text { Electrical Distance } \\
\text { - } \quad \text { Path power angle relationship } \\
\text { - } \quad \text { Substation breaker/switch configuration } \\
\text { - } \quad \text { PCADA telemetry configuration } \\
\text { - } \quad \text { Voltage and current transformers } \\
\text { - } \quad \text { Weighted least squares method } \\
\text { - } \quad \text { Measurement accuracies } \\
\text { - } \quad \text { Parallel Path Flows } \\
\text { - } \quad \text { Generator Re dispatch } \\
\text { - } \quad \text { Phe outage distribution factors } \\
\text { - } \quad \text { Generator Shift Factors }\end{array}$} \\
\hline $\begin{array}{l}\text { Performance } \\
\text { Measures }\end{array}$ & \multicolumn{2}{|c|}{$\begin{array}{l}\text { - } \quad \text { Correct mental models accessed } \\
\text { - } \quad \text { Rime it took to build the right story } \\
\text { - Time it took to take (preventative) action } \\
\text { - } \quad \text { Was the right action taken? } \\
\text { - Is the situation resolved? }\end{array}$} \\
\hline
\end{tabular}

\subsubsection{Exploring the Mediating Relationship}

\begin{tabular}{|l|l|l|}
\hline Mental Model & Trigger - Exp. Group & Trigger - Control Group \\
\hline Electrical Distance & $\begin{array}{l}\text { PSE shows that the line is out of service } \\
\text { which is a cue that the topology has } \\
\text { shifted. Participant would be notified by } \\
\text { PSE }\end{array}$ & $\begin{array}{l}\text { Participant must notice sometimes } \\
\text { minute flow changes (or lack thereof) on } \\
\text { a line impacted by line outage } \\
\text { distribution factors following an outage } \\
\text { with bad data. }\end{array}$ \\
\hline Parallel Path Flows & $\begin{array}{l}\text { PSE shows how generator re dispatch } \\
\text { does not result in flow along a certain } \\
\text { path indicating a line outage. Participant } \\
\text { would be notified by PSE }\end{array}$ & $\begin{array}{l}\text { An outaged line will not show changes in } \\
\text { flows. Cues may only be passively } \\
\text { available. }\end{array}$ \\
\hline $\begin{array}{l}\text { Generator Re } \\
\text { dispatch }\end{array}$ & $\begin{array}{l}\text { Generator re dispatch would induce a } \\
\text { change in the power flow, in which the } \\
\text { PSE would determine a line outage and } \\
\text { bad data. Participant would be notified } \\
\text { by PSE }\end{array}$ & $\begin{array}{l}\text { Generator re dispatch would not change } \\
\text { the power flow as expected. }\end{array}$ \\
\hline
\end{tabular}




\begin{tabular}{|c|c|c|}
\hline $\begin{array}{l}\text { Line Outage } \\
\text { Distribution Factors }\end{array}$ & $\begin{array}{l}\text { Line outages affecting a bad data point } \\
\text { would indicate the source of the bad data } \\
\text { due to line outage distribution factors } \\
\text { changes. Participant would be notified by } \\
\text { PSE. }\end{array}$ & $\begin{array}{l}\text { Line outage distribution factors would be } \\
\text { different than expected. }\end{array}$ \\
\hline Phase Angle & $\begin{array}{l}\text { Phase angles between busses would } \\
\text { indicate that a line outage has occurred, } \\
\text { and bad data would be identified. } \\
\text { Participant would be notified by PSE }\end{array}$ & $\begin{array}{l}\text { Phase angles would be different than } \\
\text { expected. }\end{array}$ \\
\hline $\begin{array}{l}\text { Generator Shift } \\
\text { Factors }\end{array}$ & $\begin{array}{l}\text { Line outages would affect Generator } \\
\text { Shift Factors, and subsequent changes } \\
\text { to Generator MW setpoints (due to } \\
\text { generator re dispatch for example), PSE } \\
\text { would indicate line outage and bad data. } \\
\text { Participant would be notified by PSE }\end{array}$ & $\begin{array}{l}\text { Changes to generator setpoints, due to } \\
\text { generator re dispatch for example, would } \\
\text { not affect the transmission system as } \\
\text { expected due to altered Generator Shift } \\
\text { Factors. }\end{array}$ \\
\hline $\begin{array}{l}\text { Substation } \\
\text { breaker/switch } \\
\text { configuration }\end{array}$ & $\begin{array}{l}\text { Verifies and displays topology. If } \\
\text { topology is not as expected PSE shows } \\
\text { a potential error in SCADA topology }\end{array}$ & $\begin{array}{l}\text { Based on SCADA RTU data, if data } \\
\text { indicates a line is closed, for example, } \\
\text { the SCADA system will assume such, } \\
\text { even if mathematically (and given all } \\
\text { other data sources) the line must be out } \\
\text { of service. }\end{array}$ \\
\hline $\begin{array}{l}\text { Voltage and current } \\
\text { transformers }\end{array}$ & $\begin{array}{l}\text { Operators may need to know source of } \\
\text { measurements to detect bad data }\end{array}$ & $\begin{array}{l}\text { Operators may need to know precise } \\
\text { source of measures to detect bad data }\end{array}$ \\
\hline $\begin{array}{l}\text { Weighted least } \\
\text { squares method }\end{array}$ & $\begin{array}{l}\text { Operator needs to know basis of WLS } \\
\text { method to detect bad data }\end{array}$ & Not applicable \\
\hline $\begin{array}{l}\text { Measurement } \\
\text { accuracies }\end{array}$ & $\begin{array}{l}\text { Accuracy of measurement is verified } \\
\text { mathematically. Results are displayed } \\
\text { graphically }\end{array}$ & $\begin{array}{l}\text { Accuracy of measurement is dependent } \\
\text { on proper functioning of data capture } \\
\text { equipment. Failure of such equipment is } \\
\text { transferred on to SCADA systems } \\
\text { leaving the system operator unaware of } \\
\text { inaccuracies }\end{array}$ \\
\hline PMU accuracy & $\begin{array}{l}\text { Operators needs to know PMU accuracy } \\
\text { to detect bad data }\end{array}$ & Not applicable \\
\hline
\end{tabular}

\subsection{Mode Meter/Mode Shape}

\subsubsection{Overview}

The Mode Meter and Mode Shape tools provide visualization to an area of power systems that is traditionally devoid of much real time monitoring: dynamic stability. In practice with dynamic instability, most operators are completely in the dark, with nothing more than a cryptic telephone call from a generator operator, if they're fortunate. This may or may not help in the assessment of the problem. This scenario seeks to create a condition where the system becomes negatively damped, the condition that is required for dynamic instability, and eventually experiences system islanding as a result. 


\begin{tabular}{|c|c|c|}
\hline \multicolumn{3}{|c|}{ Mode Meter/ Mode Shapes } \\
\hline & Experimental Group & Control Group \\
\hline Tools & $\begin{array}{ll}\text { - } & \text { Mode Meter } \\
\text { - } & \text { Mode Shapes } \\
\text { - } & \text { PowerSimulator }\end{array}$ & - PowerSimulator \\
\hline Mental Models & \multicolumn{2}{|c|}{$\begin{array}{l}\text { - } \text { Dynamic Stability } \\
\text { - Generator - transmission system power angle characteristics } \\
\text { - } \quad \text { Un-damped Electro-mechanical Oscillations (Tacoma Narrows Bridge, Glider) } \\
\text { - } \quad \text { Generatical modes of oscillation } \\
\text { - } \quad \text { Generator turbine governor loops } \\
\text { - } \quad \text { Pxcitation systems } \\
\text { - } \quad \text { Powitive feedback loops } \\
\text { - Generator re dispatch }\end{array}$} \\
\hline $\begin{array}{l}\text { Performance } \\
\text { Measures }\end{array}$ & \multicolumn{2}{|c|}{$\begin{array}{l}\text { - Correct mental models accessed } \\
\text { - Time it took to build the right story } \\
\text { - Right cues used to build the story } \\
\text { - Time it took to take (preventative) action } \\
\text { - Was the right action taken? } \\
\text { - Is the situation resolved? }\end{array}$} \\
\hline
\end{tabular}

\subsubsection{Exploring the Mediating Relationship}

\begin{tabular}{|l|l|l|}
\hline Mental Model & Trigger - Exp. Group & Trigger - Control Group \\
\hline Dynamic Stability & $\begin{array}{l}\text { Displays the damping on various modes } \\
\text { present in a power system. When } \\
\text { negatively damped, participant may have } \\
\text { time to respond and prevent dynamic } \\
\text { instability. Shows both modes, and } \\
\text { locations of modes, which allows the } \\
\text { participant to determine the optimal } \\
\text { location to respond. }\end{array}$ & $\begin{array}{l}\text { Dynamic instability is indicated by rapid } \\
\text { power transfers and potential } \\
\text { communication by generator } \\
\text { operators/reliability coordinators. } \\
\text { Determining that the problem is in fact } \\
\text { dynamic instability is made difficult } \\
\text { because there could be many causes for } \\
\text { power transfers, there is limited time to } \\
\text { react, and the actual locations of the } \\
\text { contributing generators may be } \\
\text { unknown. }\end{array}$ \\
\hline Critical Modes of & Shown as a graphical representation of a & Not shown. \\
\hline
\end{tabular}




\begin{tabular}{|c|c|c|}
\hline Oscillations & mode. & \\
\hline $\begin{array}{l}\text { Positive Feedback } \\
\text { Loops }\end{array}$ & $\begin{array}{l}\text { Shown through the damping } \\
\text { characteristic both on the mode } \\
\text { meter/mode shape }\end{array}$ & Not shown. \\
\hline $\begin{array}{l}\text { Generator Re } \\
\text { dispatch }\end{array}$ & $\begin{array}{l}\text { Optimal location Indicated graphically } \\
\text { through the mode shapes application }\end{array}$ & $\begin{array}{l}\text { Location of optimal generator re dispatch } \\
\text { not specific. Mental model may not be } \\
\text { accessed if dynamic instability (story) is } \\
\text { not properly assessed. }\end{array}$ \\
\hline Modes & $\begin{array}{l}\text { Recorded and shown graphically through } \\
\text { mode shapes and mode meter }\end{array}$ & Not shown. \\
\hline $\begin{array}{l}\text { Generator - } \\
\text { transmission system } \\
\text { power angle } \\
\text { characteristics }\end{array}$ & $\begin{array}{l}\text { Power angle characteristic is the } \\
\text { foundation of system instability and } \\
\text { strength of electro-mechanical coupling } \\
\text { between generators. }\end{array}$ & $\begin{array}{l}\text { Power angle characteristic is the } \\
\text { foundation of dynamic instability and } \\
\text { strength of electro-mechanical coupling } \\
\text { between generators. }\end{array}$ \\
\hline $\begin{array}{l}\text { Generator } \\
\text { Excitation/Power } \\
\text { System Stabilizers }\end{array}$ & $\begin{array}{l}\text { Visualization of modes leads to the } \\
\text { introduction of mode creation due to new } \\
\text { mental models related to the operation of } \\
\text { generator excitation and power system } \\
\text { stabilizer systems }\end{array}$ & Not shown. \\
\hline $\begin{array}{l}\text { Generator turbine } \\
\text { governor loops }\end{array}$ & $\begin{array}{l}\text { Visualization of modes leads to the } \\
\text { introduction of mode creation due to new } \\
\text { mental models related to the generator } \\
\text { turbine loops }\end{array}$ & Not shown. \\
\hline $\begin{array}{l}\text { Generator electro- } \\
\text { mechanical } \\
\text { oscillations }\end{array}$ & $\begin{array}{l}\text { Visualization of modes leads to the } \\
\text { introduction of mode creation due to new } \\
\text { mental models related to the generator } \\
\text { electro-mechanical oscillations }\end{array}$ & Not shown. \\
\hline $\begin{array}{l}\text { Generator transient } \\
\text { reactance equivalent } \\
\text { circuit model }\end{array}$ & $\begin{array}{l}\text { Path reactances, including generator } \\
\text { internal reactances, are the basis for the } \\
\text { strength of the electro-mechanical } \\
\text { coupling between groups of generators. }\end{array}$ & Not shown \\
\hline
\end{tabular}


THIS PAGE INTENTIONALLY LEFT BLANK 


\section{Summary and Conclusions}

This report described human factors evaluation of four visualization tools (Graphical Contingency Analysis, Force Directed Graphs, Phasor State Estimator and Mode Meter/ Mode Shapes) developed by PNNL, and proposed test plans that may be implemented to evaluate their utility in scenario-based experiments.

An initial human factors evaluation focused on a heuristic-based impact assessment of the extent of facilitation of operator performance by the proposed analysis and visualization tools. The heuristic evaluation technique identified expected operational utility and the most likely beneficiary (e.g., Reliability Coordinators, Transmission Operators or Planning Engineers, or perhaps higher level policy decision makers) of each of the visualization tools.

A second, more indepth analysis of the visualization tools was conducted to identify specific experimental studies that may be run to measure the impact of the visualization tool on decision making performance. The analysis considers the operator's possible use of requisite mental models to assess the level of understanding and the process used by the operator in working through the experimental scenarios. Experiments were proposed to compare operator performance with and without the use of the visualization tool(s) to measure their efficacy and impact.

Underlying the current analysis, findings, and proposed experiments is an integrated decision model (IDM) developed by Greitzer et al. (2009). Adapted from current models of naturalistic decision making, the IDM describes decision making by articulating several cognitive processing stages, conceptualized using mediating variables such as mental models. The first stage is situation assessment, where mental models and cues from the environment are used to build an accurate story that describes the situation. The next stage is the determination of which action to take in order to positively affect the situation. Mental simulations, based on mental models, help predict the outcome of different actions and point towards an optimal decision. Finally, the new situation is assessed and a determination is made as to whether the situation is resolved or if the pattern needs repeating.

It is recommended that a follow-on study be conducted to run the proposed experiments and report results. The expected outcome of the proposed experiments is an assessment of the nature and extent of the impact of power grid visualization tools developed by PNNL. Specifically, in accordance with the IDM framework, the experiments will seek to determine if the visualizations trigger appropriate mental models needed by system operators to understand the state of the system in real time and promote effective and timely actions. The expectation is that the framework and experimental method specified in the proposed study will be useful for identifying performance impacts and utility of power grid analysis and visualization tools developed not only by PNNL but also by other R\&D groups, with evaluations that may be conducted on behalf of industry and DOE stakeholders. In addition, the establishment of the models and the infrastructure for data collection within the EIOC will demonstrate the utility of the EIOC not only as a test bed supporting system evaluation, but also as an environment to 
conduct grid operator training. Ultimately, it is hoped that the human factors and test/evaluation methodology, applied within the PNNL EIOC, will lead to the deployment of more effective tools and visualizations that will ultimately improve the performance of power grid operators, supervisory personnel, and regulatory policy makers through enhanced situation awareness and cognitive decision support, and ultimately create more reliable and secure electric power grid interconnection and operations. 


\section{References}

Campbell, D. T., \& Stanley, J. C. (1966). Experimental and quasi-experimental designs for research. Chicago: Rand McNally.

Cohen, M. S., Freeman, J. T. \& Thompson, B. B. (1997). Training the Naturalistic Decision Maker (Chapter 25), in C.E. Zsambok \& G. Klein (eds.), Naturalistic Decision Making. Mahwah, NJ: Lawrence Erlbaum Associates.

Endsley, M. R. (1995). Measurement of situation awareness in dynamic systems. Human Factors, 37, 32-64.

Endsley, M. R. (1997). The role of situation awareness in naturalistic decision making (Chapter 26), in C.E. Zsambok \& G. Klein (eds.), Naturalistic Decision Making. Mahwah, NJ: Lawrence Erlbaum Associates.

Greitzer, F. L., Schur, A., Paget, M., \& Guttromson, R. T. (2009). A sensemaking perspective on situation awareness in power grid operations. Proceedings, IEEE Power \& Energy Society Annual Meeting, 20-24 July 2008, Pittsburgh, PA. PNNL-SA-58145

Greitzer, F. L., Podmore, R., Robinson, M., \& Ey, P. (2009). Naturalistic Decision Making for Power System Operators. Paper presented to the Ninth Annual Naturalistic Decision Making Conference, London, England. Also to be published in the International Journal of HumanComputer Interaction (in press).

Klein, G. A. (1993). A Recognition Primed Decision (RPD) Model of Rapid Decision Making. In G.A. Klein, J. Orasanu, R. Calderwood \& C.E. Zsambok (eds.), Decision Making in Action: Models and Methods. Norwood, NJ: Ablex Publishing.

Nielsen, J., and Molich, R. (1990). Heuristic evaluation of user interfaces, Proceedings of the ACM CHI'90 Conference, Seattle, WA, 1-5 April, 249-256.

Nielsen, J. (1994). Heuristic evaluation. In Nielsen, J., and Mack, R.L. (Eds.), Usability Inspection Methods. New York, NY: John Wiley \& Sons.

U.S.-Canada Power System Outage Task Force, 2004, "Final Report on the August 14, 2003 Blackout in the United States and Canada: Causes and Recommendations."

Weick, K. E. (1995), Sensemaking in organizations. Thousand Oaks, CA: Sage Publications. 


\section{Appendix A: Application of Integrated Decision Model}

The Integrated Decision Model (IDM), illustrated in Figure 1 of the report, is reproduced below to support the explanation of the model and its application.

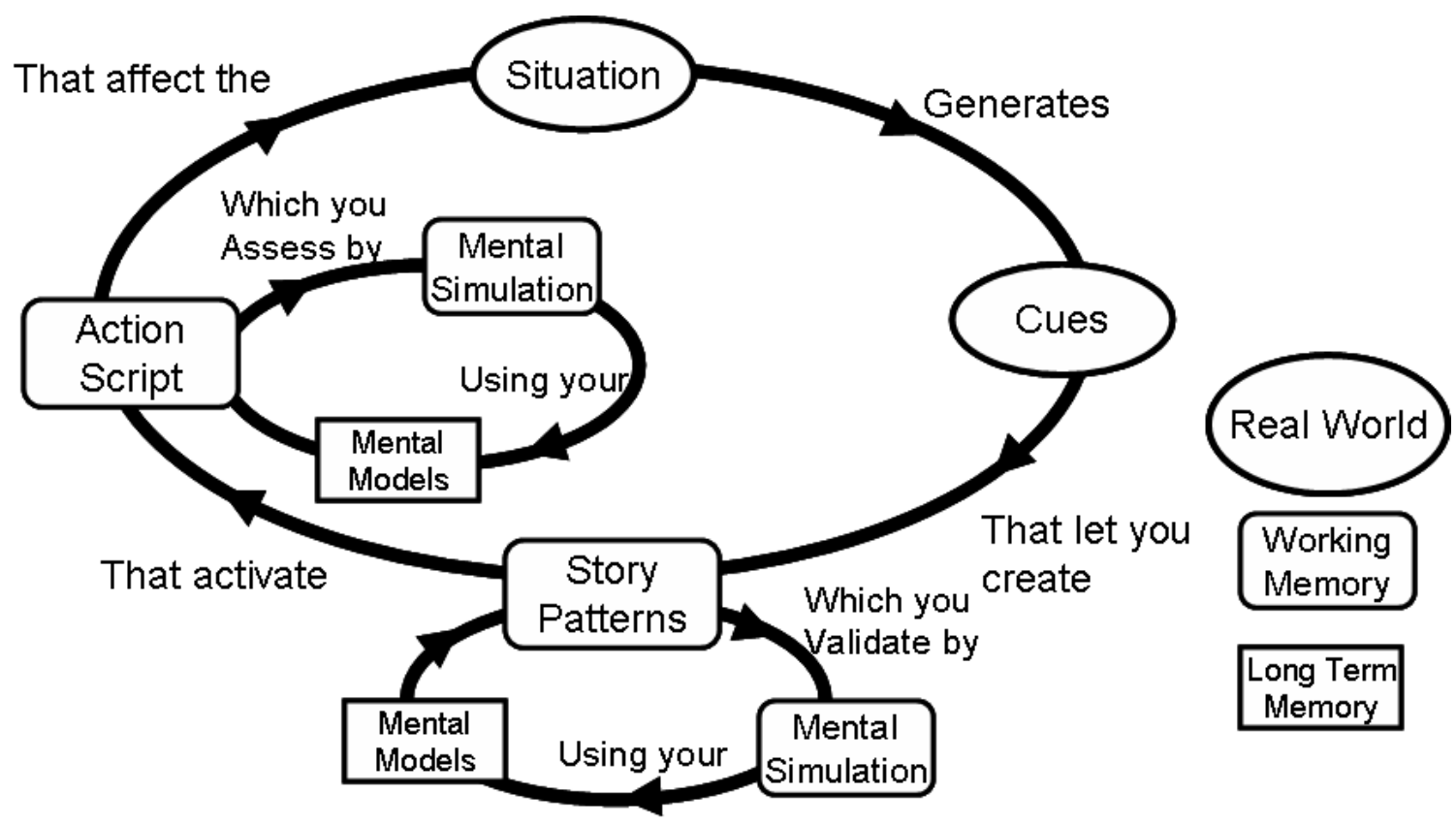

Figure A-1. Integrated Decision Model

\section{A.1 Situation}

The situation or state of the system will vary based upon a number of factors including, time of day, current and forecasted system load and weather conditions for local and interconnected areas, current and forecasted generation and transmission maintenance outages for local and interconnected areas, current and forecasted interchange levels and flow patterns.

\section{A.2 Cues}

The situation or state of the system is presented to the system operator from a variety of sources including: measurements from the SCADA system and data links, communications with plant operators, substation operators, line crews, distribution operators, neighboring control area operators, reports on results of on-line analysis programs, results from operation planning studies and operation planning engineers. The SCADA system contains cues on numerous displays including system summary displays, alarm logs, abnormal summaries, charts, map boards and system overview displays. Even in a medium sized Transmission Operator there are thousands of variables to potentially review and consider. The saying "too much data and not enough information" is often used to describe the user interface problem. 
An experienced operator will be more sensitive to and will have a greater appreciation for various explicit and sometimes subtle inputs than a novice operator. The more experienced operators can extract and focus on the key variables that summarize the overall situation e.g., MVAR reserves in an area, voltage stability $P-V$ margin, sustained ramping capacity, spinning reserves and ACE.

Visualization tools should facilitate the operator's recognition and use of appropriate cues.

\section{A.3 Story}

Using the cues to build a Story is a critical step in the decision making process. By using the mental models and the mental simulations to build a complete and consistent story the operators increase their situation awareness.

The building of the Story corresponds to increasing the operator's level of situation awareness from Level 1 through Level 3 (Endsley, 1997):

- SA Level 1 - "WHAT": Perceiving critical factors in the environment.

- SA Level 2 "SO WHAT": Understanding what those factors mean, particularly when integrated together in relation to the person's goals.

- SA Level 3 "NOW WHAT"; Understanding what will happen in the near future.

The more experienced operators are able to monitor a wider range of cues and are able to build a more complete and consistent Story compared to less experienced operators.

Experienced decision makers work with evolving situation models or stories. They assimilate new cues with these models as a reference, while at the same time looking for gaps and conflicts while being prepared for surprises. When an unexpected or conflicting event occurs they elaborate the story to take it into account. They maintain an awareness of their elaborative efforts and stay alert to the danger of going to far (Cohen, 1997).

Visualization Tools should support the system operator in the timely development of a complete and consistent "Story" about the current system conditions. This requires stimulating the operator to recognize and retrieve appropriate mental models from long term memory and conduct appropriate mental simulations in working memory.

The aspect of triggering the correct mental models from long term memory and guiding the correct mental simulations in working memory is not normally considered within the scope of traditional visualization tools.

Because traditional visualization tools focus on presenting cues to the system operator, they are primarily oriented toward facilitating Level I SA.

\section{A.4 Mental Models}

An expert power system operator has thousands of relevant mental models in his/her long -term memory. Mental models range along a continuum from very simple to very complex. Mental models are required for but not limited to: 
- Physical, mechanical and electrical characterizations of all the different system components, e.g., breaker, generator, faulty breaker position indicator, generator MVAR output, independent islands, indications of line flows, line breaker, line capacitance.

- Physical, mechanical and electrical characterizations of how components work together, e.g. interconnect two areas, isolate line, lower system voltage, synchronize islands, transfer line capacitance from your system to our system, trying to synchronize across breakers.

- The abilities, sensibilities, limitations and motivations of all the people that form part of the system operator's extended team.

- Operating procedures and policies

The mental models are used to validate that a complete and consistent Story has been built to explain the current situation. The mental models are also used to anticipate the effects of candidate control actions.

Visualization tools can also support triggering of correct mental models:

- Electrical distance between two sets of generators has changed.

- System is close to voltage collapse

- System is close to dynamic instability

- System is vulnerable to transient instability.

\section{A.5 Mental Simulations}

The experienced system operator performs a mental simulation by first retrieving certain relevant mental models from long-term memory. The operator then runs a mental simulation using these mental models and checks to see if there is consistency with the cues that are being observed. Sometimes these mental models need to be triggered to be activated and retrieved from long-term memory. There is sometimes difficulty in connecting mental models together. In retrospect with experience the connections can become a lot more obvious.

As the operator processes the cues, he or she is running consistency checks. "Are the MVARs flowing downhill on voltage? Is the total MW into the bus equal to the total MW out of the bus? Is the line loaded above or below the surge impedance loading level? Are the MVARs for the open ended line flowing into the bus?"

Once the operator decides which corrective actions to implement, he or she tests them using mental models to anticipate their impact on the system.

The experienced operator can usually estimate the directional trends that will occur for various control actions. For example, adding capacitance will increase local bus voltages, a line will be unloaded by decreasing generation at the sending end and increasing generation at the receiving end. However, estimating the quantitative effects of control actions when the system is an unusual operating condition can be very difficult. 
A simulation or contingency analysis tool may be able supplement the mental models of the operators. However, in many cases even if they are available, there may not be sufficient time to use these tools.

Experienced operators know the art of how to control the system a little at a time, monitor the changes and then decide on a more definitive action.

Simulations can test the depth of an operator's understanding of the mental models. An operator may know what output will happen. But they may also need to know why it happens, much it will happen and the exception cases.

\section{A.6 Action Scripts}

Based upon the development of a complete and consistent story concerning the current situation the experienced operator will develop an action script to correct the existing situation and correct for any anticipated contingencies.

The NERC policy states that these corrective actions should be implemented as quickly as possible without regard to the economic cost. If there are lines or transformers that are exceeding their Short Term Emergency Ratings or buses that are exceeding their voltage limits, the System Operator has the authority and responsibility to implement the necessary remedial actions, including shedding load, to alleviate these overloads and violations. 


\section{Appendix B: Topics Covered During Pre Experiment Class}

This list describes the topics that will be reviewed in the pre experiment class.

- Parallel Path Flows

- Line Overloads

- Declaration of Alert and Emergency States

- Generator re dispatch

- Generator shift factors

- MVAR support

- Shunt Capacitors

- Dynamic Stability

- Oscillations (Tacoma Narrows Bridge, Glider)

- Positive feedback loops

- Modes

- Line Outage Distribution Factors

- Electrical distance

- Transient stability

- Generator Reserves

- Faults

- Relays

- Protections systems

- Pole slipping

- System separation

- Energy Functions

- Interchange

- Line impedance

- Voltage Angles

- SCADA systems

- State Estimator Systems

- Measured Data vs. Calculated data

- System monitoring

- Make before break

- Transmission Switching

- Open Ended lines

- Generator voltage support

- Phase Angles

- Reclosing breakers 
THIS PAGE INTENTIONALLY LEFT BLANK

B-2 


\section{Appendix C: Graphical Contingency Analysis Experiment- Technical Details}

\section{C.1 Pre-Scenario Instructions}

- Participant is given a survey

- Review the Visualization tool interactions (for experimental group only)

- Participant is told to run the simulator reliably and securely as if it were the real system

- Participant is asked to explain their actions and the reasons for those actions out loud while they run the scenario

- Participant is told to declare an Alert State and/or Emergency State as if it were the real system.

- Participant is told that they can assume the position of the external operators in the case of adjusting interchange schedules (and adjusting external unit output if need be)

\section{C.2 Scenario Instructions}

- Participant is not given any specific instructions for operation of power system. While monitoring the system, they will experience a triple outage.

- They are told that there is a storm expected to come through the PALCO system in the next 15 minutes and run through the PALCO system for the next 2 hours

- Over the next 15 minutes, they will experience 3 line outages in short succession. The system will be in a very precarious position. Another outage could put the system in a voltage collapse scenario or imaginary power imbalance. The operator must recognize this story and react in a limited amount of time.

- For the experimental group, they will have access to a graphical contingency analysis result which will indicate the most severe contingencies.

- For the control group, a full list will be provided on the contingencies. They will be required to filter through the list and judge which contingency(/ies) are important.

- A fourth outage will occur at the most severe contingency point. If the operator reacts in time, they will be able to prevent the voltage collapse, otherwise there will be a blackout following the trip of the fourth contingency.

\section{C.3 Possible Scenario:}

Generator Positions:

\begin{tabular}{|c|c|c|c|}
\hline Name & Mode & MW & \multirow{7}{*}{$\begin{array}{l}\text { PAL } 2007 \text { Model. 2PM Base Case. } \\
\text { Outage of LOCH-HOM }(60 \mathrm{sec}) \\
\text { Outage of FAR1-GRA, FAR2-GRA (90 sec) } \\
\text { Outage of OAK1-CRA, OAK2-CRA (120 sec) } \\
\text { Participant has access to (graphical) contingency } \\
\text { analysis at this point. }\end{array}$} \\
\hline EX1 & MAN & 181 & \\
\hline EX2 & MAN & 181 & \\
\hline EX3 & MAN & 181 & \\
\hline EX4 & LFC & 262 & \\
\hline CRA1 & LFC & 375 & \\
\hline CRA2 & LFC & 375 & \\
\hline
\end{tabular}




\begin{tabular}{|l|l|l|l|}
\hline LOCH & MAN & 1150 & \multirow{2}{*}{ Most Severe contingency: BAK-AMUS line. } \\
\hline AMUS & MAN & 200 & \\
\hline HOMER & LFC & 400 & \multirow{3}{*}{ The BAKER to AMUS line will go out of service at 15} \\
\hline DOYLE & LFC & 540 & The \\
FARLIE & MAN & 400 & minutes after scenario begins. \\
\hline GRANGE & OFF & 0 & \\
\cline { 1 - 2 } UXBRIDGE & OFF & 0 & \\
\hline
\end{tabular}

Possible Solution:

- The participant should turn on the GRANGE unit and ramp up to 350MW.

- The participant should turn Homer on MAN mode and ramp up to $450 \mathrm{MW}$.

- The participant should shed load at OAKDALE and AMUS to reduce line flows

- The participant can trip BAKER unit offline to reduce flows. Alternatively, they can reduce BAKER to minimum output.

- The participant can open HOMER-JENK to move flows to reduce overloads.

- The participant can reduce output of CRAWFORD 1 and 2 Generators to reduce overloads.

- The participant can reduce Locher to $\sim 1080$ to reduce some overloads.

- The participant could cut all external ties except that to Jenkin, then open JENKIN to LOCHER, then increase external output to reduce line overloads in NE.

- The participant should shed load at STANTON and COPLEY to reduce excessive overload on STAN-BEAV,

- RICTER-BEAV lines should BAKER-AMUS be outaged.

- The participant should turn on Capacitors at Copley Manor to reduce low voltage in NW.

A combination of these efforts is required to prevent a blackout resulting from MVAR imbalance.

The participant will have 5 minutes to act before inverse time current relays trip the BAKERAMUS line. After 10 minutes the the BAKER-AMUS line (most severe contingency) will go out,

\section{C.4 Human Factor Performance Measures}

\begin{tabular}{|l|r|}
\hline Situation & 1 Problem Recognition \\
Awareness & a. Recognition of All Outages? \\
& b. Declare Alert State - Time? \\
Cues/Story Mental & 2 Construction of story \\
Models & a. Time? \\
& b. Relevant cues identified? \\
& i. Compare all relevant cues with those identified. \\
& Pre-contingency Analysis \\
\hline
\end{tabular}




\begin{tabular}{|c|c|}
\hline & $\begin{array}{l}\text { ii. Relevant cues: } \\
\text { 1. Overload on BAK-AMU 150\% } \\
\text { 2. Overload on OAK2-AMU } \\
\text { 3. Overload on OAK1-AMU } \\
\text { 4. Near overloads on BAK-AMU } \\
\text { 5. Overload D on } \\
\text { 6OY>RIC>BEA>STAN>STAN Overload on LOCH-HOM } \\
\text { 7. Overload HOM1-GRA } \\
\text { 8. Overload HOM2-GRA } \\
\text { 9. Grange Unit offline } \\
\text { 10. Uxbridge Unit offline } \\
\text { 11. Low voltage in NW. } \\
\text { 12. Load Centers } \\
\text { 13. Weather expectations } \\
\text { 14. Connectivity of system resulting in } \\
\text { Overloads } \\
\text { c. Relevant cues identified? } \\
\text { i. Compare all relevant cues with those identified. } \\
\text { Post Contingency Analysis } \\
\text { ii. Relevant cues: } \\
\text { 1. System Outage } \\
\text { d. Correctness of Story? } \\
\text { i. Compare access of mental models that are } \\
\text { necessarily accessed to construct the story? }\end{array}$ \\
\hline Actions Taken & $\begin{array}{l}3 \text { Control Actions } \\
\text { a. Time to reduce overloads? } \\
\text { b. Time to restore voltage support? } \\
\text { c. Total load shed? } \\
\text { d. Network Reconfiguration? Why? } \\
4 \text { Condition of system after BAK-AMUS contingency? } \\
\text { a. Withstand the Baker-Amus line contingency? } \\
\text { b. Line overloads and violations after contingency? }\end{array}$ \\
\hline
\end{tabular}

\section{C.5 Technical Setup}

- A static graphical contingency analysis will be created for:

- PAL 2007 Model. 2PM Base Case.

- Outage of LOCH-HOM

$\circ$ Outage of FAR1-GRA, FAR2-GRA

- Outage of OAK1-CRA, OAK2-CRA

- Generator positions described for Scenario 1

- User will have access to the GCA result

- Experiment will end following a blackout or successfully withstanding the BAK-AMUS line outage contingency.

- The system map and overloads that results from BAK-AMUS outage will be occurred. 


\section{Appendix D: Force Directed Graph Experiment-Technical Details}

\section{D.1 Pre-Scenario Instructions}

- Participant is given a survey

- Review the Visualization tool interactions (for experimental group only)

- Participant is told to run the simulator reliably and securely as if it were the real system

- Participant is asked to explain their actions and the reasons for those actions out loud while they run the scenario

- Participant is told to declare an Alert State and/or Emergency State as if it were the real system.

- Participant is told that they can assume the position of the external operators in the case of adjusting interchange schedules (and adjusting external unit output if need be)

\section{D.2 Scenario Instructions}

- Participant is not given any specific instructions for operation of power system. While monitoring the system, they will experience an outage of the DOY-CRA Double Circuit lines.

- They are told that there is a storm expected to come through the PALCO system in the next 15 minutes and affect the PALCO system for the next 2 hours.

- For the experimental group, a FDG will show the new electrical diagram after the outage. The FDG will be weighted on the node by bus Voltage Angle and on the link by impedance.

- For the control group, they must use the standard displays to recognize the weakness of the system. This will primarily come through the phase angle measurements taken at every bus in the system.

- The scenario ends with a fault put on the HOMER 1 bus for 0.4 seconds and subsequent outage of the Locher-Homer line. The resulting system state will be recorded.

- The fault will be applied after 15 minutes after scenario start.

\section{D.3 Possible Scenario:}

- PALCO 2007

- 2PM Base Case

- There is a $450 \mathrm{MW}$ schedule between PALCO and External systems.

- Baker unit is offline and unavailable for this scenario.

- Ricter Capacitors are online.

- UxBridge online at $0 \mathrm{MW}$.

- Farlie, Homer, and Doyle units are operating at 1100MW, $515 \mathrm{MW}$, and $575 \mathrm{MW}$ respectively to support the interchange, and other PALCO units have reduced output.

- Locher unit is at $975 \mathrm{MW}$. Crawford 1 and 2 are on LFC at around $307 \mathrm{MW}$. External $1,2,3$ are at $80 \mathrm{MW}$, External 4 is on LFC and around $120 \mathrm{MW}$. 
- Within a few minutes, the operators will experience an outage of the DOY-CRA 230kV lines.

- This outage leaves the PALCO susceptible to separation should there be a fault near a HOMER bus. If a fault is present for 0.4 seconds, this will separate the system into two islands. The resulting protection relaying will occur on the LOCHER to HOMER line.

- If the large power flows emanating from DOYLE, FARLIE, and HOMER are not reduced, then the fault will result in separation into two islands. The fault will cause protection system and RAS schemes to separate along the lower voltage network.

- Before the outage, the angle difference between the Doyle and Crawford bus is around 7 degrees. After the outage, the angle difference is around 42 degrees. Before the outage the power transfer along the DOY-CRA lines is around 320MW. Angle difference between Farlie and Crawford after outage is around 30 degrees.

- An ideal solution would be to run a generator dispatch and reduce HOMER generation and FARLIE generation, while increasing generation at LOCHER and EXTERNAL. This would necessarily require a reduction in the interchange schedule. In addition the participant may elect to drop load Stanton, Copley, Copley Manor, Uxbridge, and increase generation at UxBridge

\section{D.4 Human Factor Performance Measures}

\begin{tabular}{|c|c|}
\hline $\begin{array}{l}\text { Situation } \\
\text { Awareness }\end{array}$ & $\begin{array}{c}1 \text { Problem Recognition } \\
\text { a. Time? }\end{array}$ \\
\hline $\begin{array}{l}\text { Cues/Story Mental } \\
\text { Models }\end{array}$ & $\begin{array}{l}2 \text { Construction of story } \\
\text { a. Time? } \\
\begin{aligned} \text { b. Relevant cues identified? } \\
\text { i. Compare all relevant cues with those identified. } \\
\text { ii. Possible Cues } \\
\text { 1. Low voltage in NW } \\
\text { 2. Line overloads on BEAV-RICT } \\
\text { 3. Angle difference between Doyle and } \\
\text { Crawford and Farlie and Crawford? } \\
\text { 4. Large Power transfer from SW to NW and } \\
\text { NE } \\
\text { c. Correctness of Story? } \\
\text { i. Compare access of mental models that are } \\
\text { necessarily accessed to construct the story? }\end{aligned}\end{array}$ \\
\hline Actions Taken & $\begin{array}{l}3 \text { Control Actions } \\
\text { a. Time? } \\
\text { b. Correctness of Control actions to positively affect the } \\
\quad \text { situation? } \\
\quad \text { i. Compare access of mental models to project a } \\
\quad \text { positive action vs. those necessary? }\end{array}$ \\
\hline
\end{tabular}




\section{D.5 Technical Setup}

- This scenario uses the TSTAB transient stability program to verify transient outcomes.

- TSTAB will be used prior to the fault using current generator positions to determine whether the system separates.

- System separation points will be based on expert estimation

- The force directed graph technology will be created using the PALCO 2007 system. A case will be created for a before and after state for the outage of the DOY-CRA 1 and 2 lines.

- As an enhancement, the FDG could be accessed dynamically after the participant makes changes to the generator set points.

- Note, as of submission of this paper, the pre and post outage results have been preliminarily verified using the TSTAB program. 


\section{Appendix E: Phasor State Estimator Experiment-Technical Details}

\section{E.1 Pre-Scenario Instructions}

- Participant is given a survey

- Review the Visualization tool interactions (for experimental group only)

- Participant is told to run the simulator reliably and securely as if it were the real system

- Participant is asked to explain their actions and the reasons for those actions out loud while they run the scenario

- Participant is told to declare an Alert State and/or Emergency State as if it were the real system.

- Participant is told that they can assume the position of the external operators in the case of adjusting interchange schedules (and adjusting external unit output if need be)

\section{E.2 Scenario Instructions}

- Participant is given a number of control actions to complete in the scenario. A line outage has occurred in which the data retrieved from the field data capture units indicate that the line is in service.

- By running a series of control actions, the participant will have multiple opportunities to recognize the line outage, despite the bad data, because flows on the line (and parallel paths) will not occur as they physically should.

- The PSE will determine, through calculation that the line is outaged and notify the experimental group at the onset of the first control action. This assumes the PSE has a normal level of sensitivity to detect variances.

- The control group must rely on the recall of mental models to indicate that the line is in fact outaged and that they are truly seeing bad data instead of the real time conditions.

\section{E.3 Possible Scenario}

- PALCO 2007 System.

- 2PM Base Case.

- Oakdale-Moses $230 \mathrm{kV}$ line is lightly loaded in the base case.

- Open CB 11 and CB 12 at Oakdale to take Oakdale_Moses line out of service, but continue to show these as close on the station one-line diagram.

- Request the system operator to load the Crawford units up to $400 \mathrm{MW}$.

- In the PSE the flow on the Moses - Oakdale line should change from $10 \mathrm{MW}$ from Moses to Oakdale to $5 \mathrm{MW}$ from Oakdale to Moses. The PSE should detect that the Moses - Oakdale line is really out of service.

- The Control Group may or may not recognize that the flow on the Moses-Oakdale line has not changed and that the line is really out of service.

- Remove the Locher-Moses 1 from service. 
- The Control Group may or may not recognize that the flow on the Moses-Oakdale line has not changed and that the line is really out of service.

- Remove the Locher-Moses 2 from service. The Oakdale-Nestle line becomes overloaded.

- The Control Group may or may not recognize that the flow on the Moses-Oakdale line has not changed and that the line is really out of service.

- If the Control Group recognizes that the Moses-Oakdale line is out of service, then they can restore it to service and eliminate the overload on the Oakdale-Nestle line.

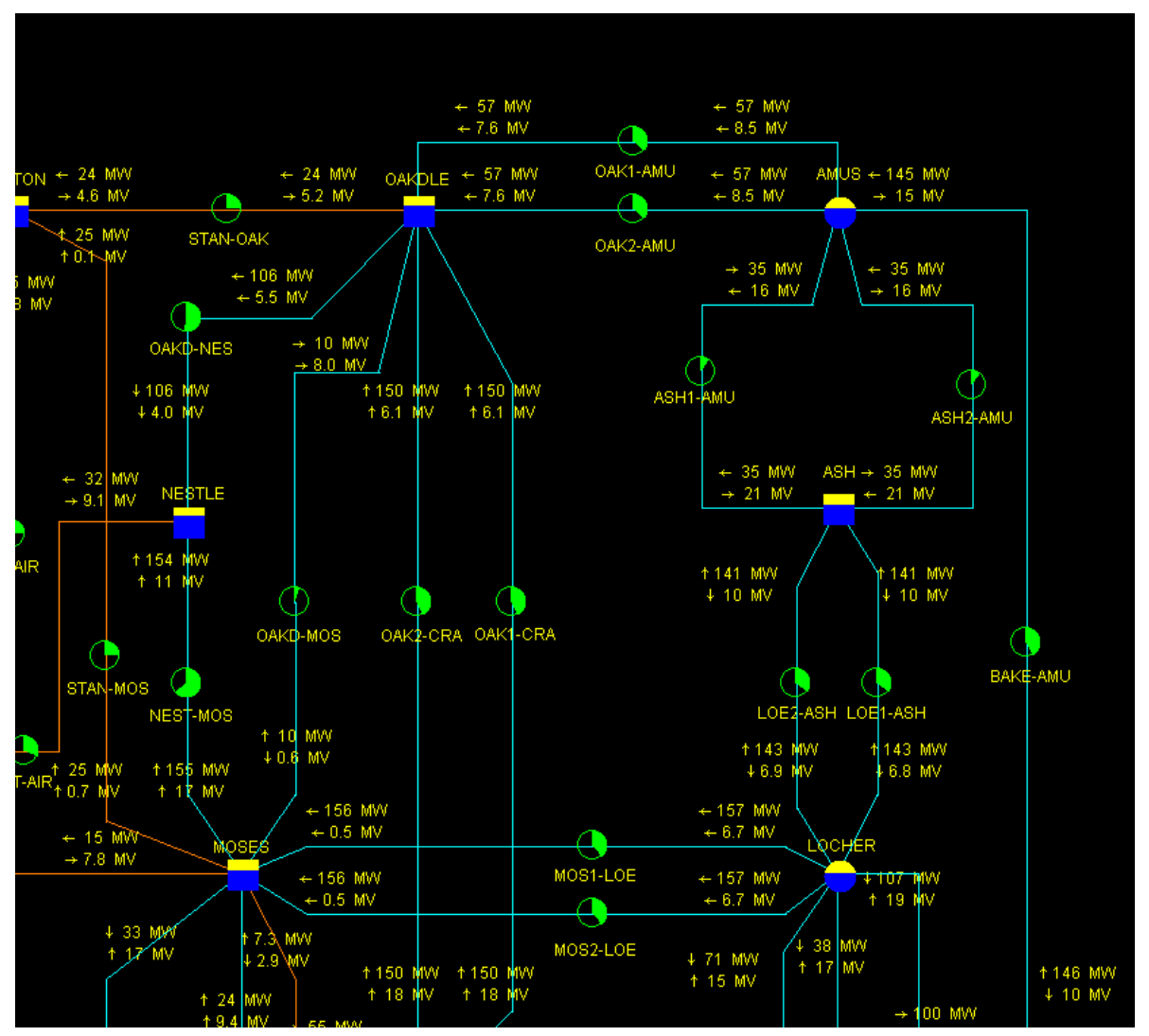

\section{E.4 Human Factor Performance Measures}

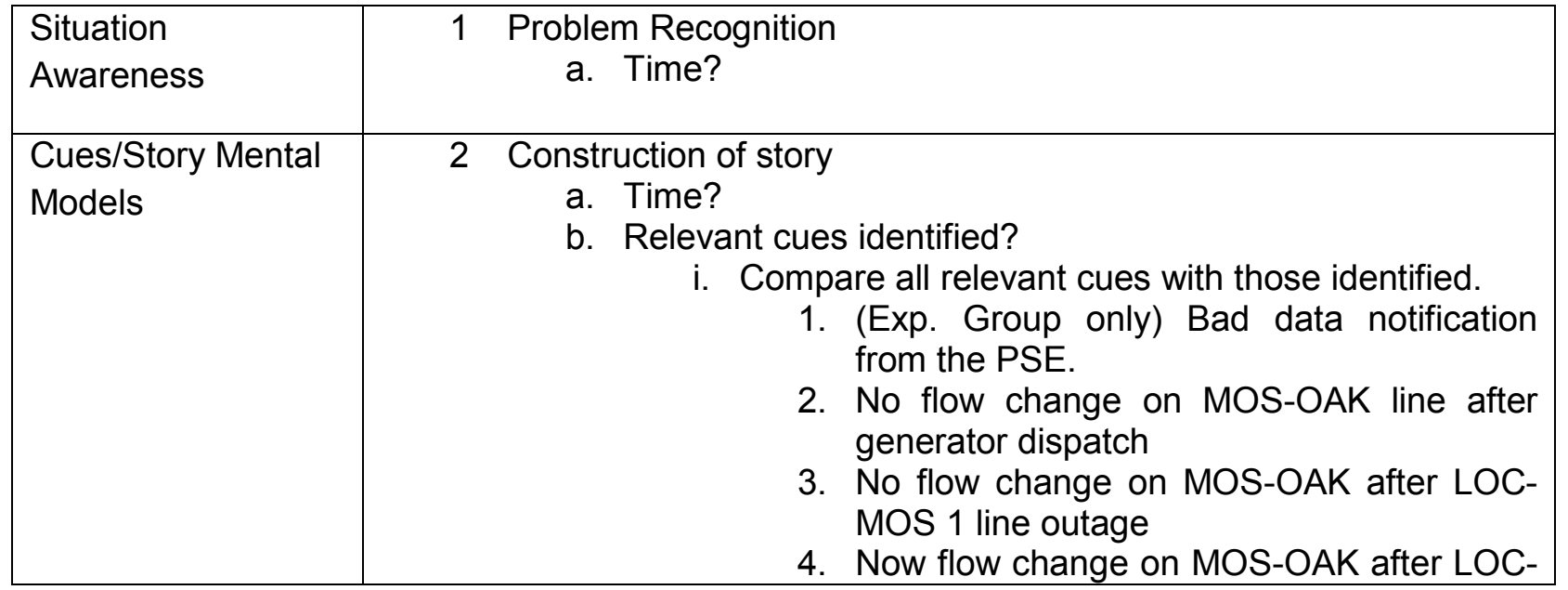




\begin{tabular}{|c|c|}
\hline & $\begin{array}{l}\text { MOS } 2 \text { line outage } \\
\text { 5. Flow changes throughout the system } \\
\text { indicate that MOS-OAK line is outaged for } \\
\text { all operations } \\
\text { c. Correctness of Story? } \\
\text { i. Compare access of mental models that are } \\
\text { necessarily accessed to construct the story? }\end{array}$ \\
\hline Actions Taken & $\begin{array}{l}\text { Control Actions } \\
\text { a. Time? } \\
\text { b. Correctness of Control actions to positively affect the } \\
\text { situation? } \\
\quad \text { i. Compare access of mental models to project a } \\
\quad \text { positive action vs. those necessary? }\end{array}$ \\
\hline
\end{tabular}

\section{E.5 Technical Setup}

- Phasor State Estimator is initialized with the PowerSimulator PALCO Network Data.

- It is assumed that PMUs are installed at every major PALCO station. Since PowerSimulator generates a power flow solution once every second, this will be acceptable.

- The Phasor State Estimator is available to notify the user of suspected bad data on regular cycles, but for a static scenario, at least before and after the generator re dispatch and switching order has been complete.

- The Phasor State Estimator provides alarming info to PowerSimulator for any suspected bad data. If necessary, the user interface screens for bad data can be statically created.

- For the experimental group, PowerSimulator will need a software enhancement to support showing incorrect CB data. Another option is to tell the system operator that the RTU for Oakdale has failed and he cannot access this diagram.

- For the control group, it is assumed that PMU data and the Phasor State Estimator are not available.

- For the control group, PowerSimulator creates the SCADA one-line representations. They will receive alarms via screenshots and equipment limit violation tabulars as indicators of limit violations should they occur. 


\section{Appendix F: Mode Meter/Mode Shapes Experiment-Technical Details}

\section{F.1 Pre-Scenario Instructions}

- Participant is given a survey

- Review the Visualization tool interactions (for experimental group only)

- Participant is told to run the simulator reliably and securely as if it were the real system

- Participant is asked to explain their actions and the reasons for those actions out loud while they run the scenario

- Participant is told to declare an Alert State and/or Emergency State as if it were the real system.

- Participant is told that they can assume the position of the external operators in the case of adjusting interchange schedules (and adjusting external unit output if need be)

- Participant is told that they cannot view the generator pop-up windows.

- Participant is told to contact the generator operator if necessary, and given a phone

\section{F.2 Scenario Instructions}

- The mode meter and mode shape tools show the dynamic stability or instability of a system.

- The participant will be monitoring the system when power flows will start to transfer back and forth from one group of generators to another group of generators.

- This will occur after the Farlie to Dawson line is faulted and goes out of service $1 / 10$ of a second later. This line outage otherwise has no major negative effect on the system as flows simply redirect according to the new network topology.

- The event will occur after 2 minutes from the start of the scenario

- The system will start to oscillate between two large units

- The oscillation will last for 90 seconds before becoming unstable (un damped)

- After 15 seconds from the start of the oscillations, the participant will receive a call from the generator operator indicating that they are experiencing large swings in their generator output

- After 30 seconds, a second call will come in from the second generator operator indicating the same.

- The swings will transfer $200 \mathrm{MW}$ back and forth every 5 seconds.

- For the experimental group, the Mode Shape and Mode Meter movie clip will be played after an alarm is sounded with the start of the oscillations. This will run concurrently to the simulator.

- For the control group, they will only get a call from the generator operator.

- Both groups must contact the generator operator(s) to adjust set points (by directing him).

- After 90 seconds following the start of the oscillation period, it is assumed that the mode has now become negatively damped and this will result in even greater swings and eventually system separation. If the system operator has performed a generator re dispatch, or some other control action which positively affects the system dynamic 
stability, then separation will be prevented. Since no tool is available to dynamically measure the dynamic stability of the system, this evaluation will be made by an expert.

\section{F.3 Possible Scenario:}

In 1996 the WECC system experienced dynamic instability between the NW generators and the Southern California Generators. The event occurred over 60 seconds and eventually led to a negatively damped/unstable situation. This scenario is designed to emulate that event on the PALCO system. Despite the size of the PALCO system, to the system operator, emulating this event will trigger all the same mental models.

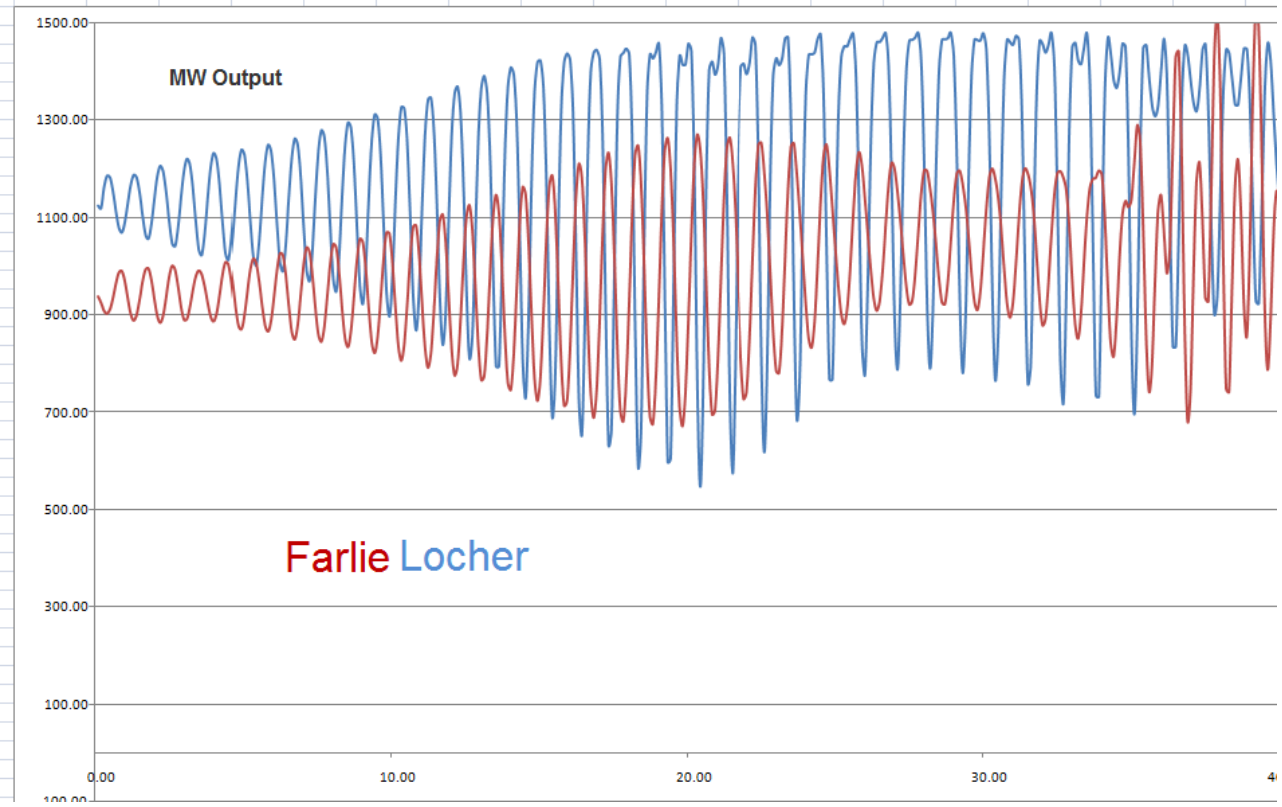

Setup:

- PALCO 2007

- 2PM Base Case

- FARLIE and LOCHER are loaded at $1100 \mathrm{MW}$ and $900 \mathrm{MW}$ respectively

- BAKER, UXBRIDGE, GRANGE are offline

- All other units are on LFC

- FARLIE and LOCHER swing against each other, exchanging $200 \mathrm{MW}$ every 5 seconds.

- Power flows across the system will rapidly change and be visible on system one line diagrams as well as the system map.

An ideal solution would be to back off the Farlie and/or Locher units from their set points. This can be accomplished by starting up Grange Unit, increasing output on Doyle or Homer, or increasing output on the External generators. 


\section{F.5 Human Factor Performance Measures}

\begin{tabular}{|c|c|}
\hline $\begin{array}{l}\text { Situation } \\
\text { Awareness }\end{array}$ & $\begin{array}{c}1 \text { Problem Recognition } \\
\text { a. Time? }\end{array}$ \\
\hline $\begin{array}{l}\text { Cues/Story Mental } \\
\text { Models }\end{array}$ & $\begin{array}{l}2 \text { Construction of story } \\
\text { a. Time? } \\
\text { b. Relevant cues identified? } \\
\text { i. Compare all relevant cues with those identified. } \\
\text { ii. Possible Cues: } \\
\text { 1. Generator operator notification } \\
\text { 2. Alarm } \\
\text { 3. Power flows rushing from one side of the } \\
\text { system to the other } \\
\text { 4. Phase angles rapidly adjusting } \\
\text { 5. Mode damping } \\
\text { 6. Mode shape location } \\
\text { c. Correctness of Story? } \\
\text { i. Compare access of mental models that are } \\
\text { necessarily accessed to construct the story? }\end{array}$ \\
\hline Actions Taken & $\begin{array}{l}3 \text { Control Actions } \\
\text { a. Time? } \\
\text { b. Correctness of Control actions to positively affect the } \\
\text { situation? } \\
\quad \text { i. Compare access of mental models to project a } \\
\quad \text { positive action vs. those necessary? }\end{array}$ \\
\hline
\end{tabular}

\section{F.6 Technical Setup}

- It is assumed that PMU units are installed and providing data for the Mode Shape/ Mode Meter. Artificial data will be created since this data is unavailable. Therefore the scenario will be a simulation of a possible case of dynamic instability.

- A prepared movie clip of the two PALCO units swinging against each other must be prepared for the scenario. This data will be created in TSTAB and outputted into the Mode Meter / Mode Shapes program.

- During the oscillations, the facilitator must manually adjust the Locher and Farlie MW set points with a ramp rate of $2400 \mathrm{MW} / \mathrm{min}=200 \mathrm{MW} / 5 \mathrm{sec}$ within PowerSimulator. An assistant facilitator may be necessary.

- The facilitator will continue the manual oscillations throughout the oscillation period.

- A static alarm message will be given to the experimental participant at the start of the oscillation.

- The movie clip will play and be available for the next 90 seconds, the length of the oscillation period, or until the operator makes a preventative control action.

- The facilitator will play the role of the generator operators. 